\title{
La redención de la culpa en el eterno retorno
}

\author{
Flávio Senra \\ Pontificia Universidad Católica de Minas Gerais (Brasil) \\ flaviosenra@pucminas.br
}

\begin{abstract}
Examinemos cómo ha obrado hasta ahora el pensamiento de que algo se repite (el año v.gr., o las enfermedades periódicas, despertar y dormir, etc.). Si bien la repetición circular es tan sólo una probabilidad o una posibilidad, también el pensamiento de una posibilidad nos puede sacudir y transformar, no sólo sacudir y transformar sensaciones o ciertas expectativas. ¡Cómo ha obrado la posibilidad de la condenación eterna! ${ }^{24}$
\end{abstract}

En el año de 1881, encontramos una gran cantidad de referencias de Nietzsche a la idea del eterno retorno, un pensamiento que marcará su obra de manera muy especial hasta el fin de su producción filosófica. Quizá este sea uno de los temas más problemáticos de su pensamiento y uno de los más sujetos a equívocos al intentar comprenderlo. Incluso Nietzsche, si se atiene a la elaboración de su reflexión sobre el tema, va desarrollando poco a poco su comprensión cada vez más trabajada del pensamiento del eterno retorno. Por lo tanto, no hay que fijarse en la particularidad de cada aforismo, publicado o no, sino intentar comprenderlo en el posible conjunto de referencias sobre el tema. Tal ha sido nuestra postura a la

24 1881, 11[203]. Este aforismo póstumo de por sí revela que el tema en Nietzsche va sufriendo a lo largo de su elaboración el proceso natural de trabajo propio en todo pensador y en todo pensar. El conjunto de ejemplos citados en el aforismo es testigo de ello. Más adelante, vamos a comprobar cómo el filósofo rompe con esta comprensión superficial del problema del retorno. Lo vamos a esclarecer tanto con otros póstumos como con la experiencia de Zaratustra. 
hora de acercarnos al pensamiento del eterno retorno, o sea, nuestro objetivo ha sido el de intentar sacar del pensamiento del eterno retorno aquel contenido fundamental que con tal doctrina se quiere expresar. Fundamentalmente, en nuestro modo de comprender el asunto, lo que Nietzsche plantea con el eterno retorno no es tanto una hipótesis que pueda ser verificada en cuanto postulado científico, sino un modo de ser del mundo y, principalmente, de estar en él. El pensamiento más abismal es el de la afirmación de la vida como creación y libertad que afirma y crea en el eterno movimiento de recreación de lo mismo de la vida, desde y para la vida.

Sin embargo, a pesar de no colocar el enfoque en hacer una revisión bibliográfica más sobre el tema del eterno retorno, no significa que estemos renunciando a la búsqueda de una interpretación que venga en nuestro auxilio a la hora de presentar en este pensamiento la posibilidad de redención de la culpa. ¿En qué sentido puede ser el eterno retorno la redención de la culpa? Comprender el eterno retorno como afirmación del mundo y de sí mismo, una apuesta por la inmanencia del mundo, pero no estática, sino dinámica (no el ser, sino el devenir) se configura como la posibilidad de revaloración y transformación - transvaloración - del modo que ha configurado el mundo como una nada, desde la apuesta moralmetafísica e idealista-transmundana del modelo sacerdotal vigente en filosofía. Sin embargo, para seguir aclarando nuestra hipótesis hemos de recurrir al texto de Nietzsche. Con ello vamos a investigar los principales elementos que servirán para nuestra aportación al tema. Puede ser que Nietzsche no lo haya pensado así. Tampoco nos vamos a ocupar de ello.

Lo fundamental al plantear el abordaje de este tema, tan complejo de por sí, es la comprensión que tenemos, según la cual el pensamiento del eterno retorno puede ser la respuesta al problema de la culpa. Intentaremos demostrarlo fijándonos en aquellos aspectos en los que se evidencia nuestra hipótesis. Empezamos por la definición del eterno retorno como nuevo imperativo ${ }^{25}$ : el imperativo de la afirmación de la vida.

25 Sabemos que no coinciden los comentaristas acerca de esta interpretación del eterno retorno como nuevo imperativo. Vattimo, por citar un ejemplo, no estaría de acuerdo con nuestra afirmación. Cf. G. VATTIMO, El sujeto y la máscara. Nietzsche y el problema de la libera- 


\section{El eterno retorno como imperativo de afirmación de la vida}

En La gaya ciencia, en el aforismo 341, aparece por primera vez publicada la idea del retorno. El tema es grave, un pensamiento abismático, trata del «peso más pesado». ¿Qué es un peso? ¿Con relación a qué se puede decir que es el más pesado? ¿Acaso existen otros pesos? Por supuesto que sí. A lo largo de la historia de la moral-metafísica, de un lado, hemos elegido un sin fin de criterios de evaluación de nuestras acciones. Nietzsche no quiere ser el que presenta un criterio más. Lo que intenta es definir $\mathrm{el}$ criterio y la medida, que justifica todo lo demás: el peso más pesado, la medida mayor que define el valor de cada apreciación y valoración moral, científica o filosófica sobre el mundo y la vida. Por otro lado $y$ en el mismo sentido, hemos elegido criterios y medidas que al final resultaron ser negadores de la propia vida $-\mathrm{y}$ en ello reside el verdadero problema. Negar la vida, en lo que en ella es representación de la voluntad de poder es negar su esencia misma. Con el texto que sigue, Nietzsche establece el nuevo criterio, el peso más pesado, la gran medida, la justa medida con que debemos medir nuestra capacidad de afirmar la vida y el peculiar cambio en la interpretación que se hace de la vida cada hombre en cuanto «totalidad de lo orgánico» y no sólo en cuanto individuo:

Suponiendo que un día, o una noche, un demonio te siguiera en la más solitaria de tus soledades y te dijera: «Esta vida, tal como la has vivido y estás viviendo, la tendrás que vivir otra vez, otras infinitas veces; y no habrá en ella nada nuevo, sino que cada dolor y cada placer y cada pensamiento y suspiro y todo lo indeciblemente pequeño y grande de tu vida te llegará de nuevo, y todo en el mismo orden de sucesión e igualmente esta araña y este claro de luna por entre los árboles, e igualmente este instante, y yo mismo. El eterno reloj de arena de la existencia es dado vuelta una y otra vez - iy a la par tú, polvito del polvo!». ¿No te arrojarías al suelo rechinando los dientes y maldiciendo al demonio que así te habló? O has experimentado alguna vez 
un instante tremendo en que le contestarías: «jeres un dios y jamás he oído decir nada tan divino!». Si esta noción llegara a dominarte, te transformaría y tal vez te aplastaría tal y como eres. ¡La pregunta ante todas las cosas: «¿quieres esto otra vez y aún infinitas veces?» pesaría como peso más pesado sobre todos tus actos! O ¿cómo necesitarías amarte a ti mismo y a la vida, para no desear nada más que esta última y eterna confirmación y ratificación?²

\subsection{Desde la experiencia de la soledad}

En su primera aparición, el pensamiento del eterno retorno surge como un interrogante iniciado por un condicionante (wenn/si), o sea, se trata de una suposición: «si algún día...», etc. ¿Qué quiere decir el afirmar (se) en cuanto suposición? Puede ser que Nietzsche no estuviera seguro de su doctrina, o, a lo mejor, que tuviera como objetivo presentarla con el carácter de un pensamiento que provoca. ¿Qué provoca el pensamiento del eterno retorno? Provoca una respuesta, es decir, dependiendo de lo que ocurra o de lo que se diga ¿cuál va a ser la respuesta? El condicionante, sumado a las figuras utilizadas en el aforismo, revela igualmente el carácter metafórico del mensaje. Entre los dos personajes de esta metáfora, la cuestión va a ser proferida por un demonio (el que provoca ruptura) que habla al hombre y lo hace en su más solitaria soledad, en la más profunda de las soledades. La soledad es la condición de aquél que no está perdido en las tareas de lo cotidiano o aturdido por el ruido del «mercado» ${ }^{3}$. Zaratustra ${ }^{4}$, el que sabe como nadie lo que es la soledad, enseña:

¡Huye, amigo mío, a tu soledad! Ensordecido te veo por el ruido de

2 Friedrich NIETZSCHE, La Gaya Ciencia, trad. Charo Grago y Ger Groot, Madrid: Akal 2001, p. 341.

3 Vid. Z, Prólogo, 3. También el discurso «De las moscas del mercado» en que se puede leer: «Donde acaba la soledad, allí comienza el mercado».

4 A lo largo del capítulo abundarán las referencias al Zaratustra de Nietzsche. Según Heidegger en la 5a lección de ¿Qué significa pensar? (trad. H. Kahnemann, Buenos Aires: Nova 1978), «esta obra de Nietzsche piensa el único pensamiento de este pensador: el pensamiento del eterno retorno de lo Mismo. Cada pensador piensa solamente un único pensamiento». La interpretación del Zaratustra está orientada fundamentalmente por la experiencia y ejercicio de lectura de esta obra en el seminario dirigido por el Prof. Navarro Cordón: Tiempo y libertad en el Zaratustra de Nietzsche impartido en el curso de invierno-primavera de 2002. 
los grandes hombres, y acribillado por los aguijones de los pequeños (...) Donde la soledad acaba, allí comienza el mercado; y donde el mercado comienza, allí comienzan también el ruido de los grandes comediantes y el zumbido de las moscas venenosas (...) Huye, amigo mío, a tu soledad: te veo acribillado por moscas venenosas. ¡Huye allí donde sopla un viento áspero, fuerte! ¡Huye a tu soledad! Has vivido demasiado cerca de los pequeños y mezquinos. ¡Huye de su venganza invisible! Contra ti no son otra cosa que venganza (...) Huye, amigo mío, a tu soledad y allí donde sopla un viento áspero, fuerte. No es tu destino el ser espantamoscas 5 .

Sin embargo, el que vive en la soledad no debe creerse en búsqueda de la «felicidad» o en el encuentro con un presunto «yo» interior. El camino puede más bien conducir al no-encuentro de lo que (o con lo que) se pretende. Probablemente puede conducir a pérdidas. Además, los que caminan en dirección a la soledad no son bien vistos por la moral del rebaño, el modo propio de ser del mercado. «¿Quieres marchar, hermano mío, a la soledad? ¿Quieres buscar el camino que lleva a ti mismo? Detente un poco y escúchame. "El que busca, fácilmente se pierde a sí mismo. Todo irse a la soledad es culpa": así habla el rebaño. Y tú has formado parte del rebaño durante mucho tiempo» ${ }^{6}$. Por esto, debemos concluir que la soledad no es un camino que sea de fácil recorrido, sino al contrario.

La soledad es el momento propio de la crisis, el tiempo de la gran decisión, el modo propio de recorrer el camino que lleva a sí mismo y en él van también nuestros demonios ${ }^{7}$. Por ello, hay que estar preparado para la soledad porque «en la soledad crece lo que uno ha llevado a ella, también al animal interior. Por ello resulta desaconsejable para muchos la soledad $»^{8}$. El aprendizaje del eterno retorno se da en el momento de la más solitaria de las soledades, en todo momento de crisis en que hay que decidir y crear o decidir crearse a sí y por encima de sí mismo, para lo cual se hace necesario el gran amor, pero también el gran desprecio.

En toda decisión está siempre el hombre solo y por lo que hay

${ }^{5} \mathrm{Z}$, «De las moscas del mercado».

6 Z, «Del camino del creador».

7 Vid. Z, «Del camino del creador».

$8 \mathrm{Z}$, «Del hombre superior». 
que decidirse es por la vida: decir-sí o decir-no. Pero, ¿qué vida es ésta por la que se ha de decidir? Además, el decir-sí y el decir-no, más que estructuras dicotómicas, deben ser comprendidos desde una perspectiva integradora. En el importante diálogo entre Zaratustra y la vida, desarrollado en el discurso «La otra canción del baile» ${ }^{9}$, Zaratustra la contempla de frente y se acerca hacia la vida como enamorado. Quizá sea este discurso uno de los más bellos en su declaración de amor a la vida, pero también el más duro. Aunque ésta se presente con frialdad, en la lejanía o en la proximidad y cercanía, allí está entregado el amante. Sin embargo, el amor de Zaratustra no es un estar dominado desde fuera por el amado, porque ningún amor puede ser vivido como pesadez. Si así fuera, la vida se asemejaría a la serpiente estranguladora. La vida no es para ser cargada como un peso, sino para ser la compañera de un baile. La vida, quizá como la sabiduría ${ }^{10}$, ama al guerrero. La vida, como la sabiduría, no ama, por lo tanto, y no quiere a los aduladores y «camellos». Al final del discurso, en medio de acusaciones de infidelidad, se despiden los amantes después de haber compartido un secreto. El secreto, el mismo que descubrimos en otros discursos de la obra ${ }^{11}$, sería la declaración de amor eterno, un amor por la eternidad como amor por la vida misma que en su profundidad es dolor y placer. Al reconocimiento de esta profundidad bajo la comprensión del anillo del retorno está llamado el hombre a la decisión: un decir-sí o un decir-no. Además, el decir-sí implica mucho decir-no, y éste, por supuesto, mucho decir-sí. Esta pseudodualidad entre las posibilidades de la respuesta no oculta la dualidad del propio mundo que es sufrimiento y placer. Pero, la afirmación del sí creador abarca incluso la negatividad de la vida, en la medida en que el placer incluye también el dolor y por eso es más profundo que el propio sufrimiento. Unir placer y sufrimiento, la afirmación trágica que ya conocemos desde los primeros textos de Nietzsche ${ }^{12}$, es lo

9 Z. «La otra canción del baile».

10 Véase también: Z, «Del leer y el escribir».

11 Vid. Z, «Los siete sellos»y «La canción del noctámbulo».

12 Sobre el tema nos reportamos al estudio del tema en los trabajos del profesor Manuel Barrios Casares: La voluntad de poder como amor, Barcelona: Ediciones del Serbal 1990, y Vo- 
que quiere eternidad. Resta saber qué vida queremos y cómo la queremos. Desde luego, el querer que no integre la totalidad sufriente y placentera de la vida y del devenir, no puede soportar el anillo del retorno como amor. Retomando el hilo conductor que afirma la soledad como el modo de estancia que torna posible la decisión, hay que comprender que en la decisión que decide por lo más esencial y profundo del mundo, de la vida y de la libertad, por supuesto, no habla el rebaño porque el rebaño es el peculiar modo en que no hay nada que decidir, no hay ninguna soledad, no hay el sí mismo, sino apenas un indiferenciado nosotros. En él sólo se vive la superficialidad y no se deja notar lo profundo del mundo. Quizá allí se revele entre los ruidos de lo cotidiano incluso un erróneo placer que nada tiene que ver con la felicidad más profunda de que nos habla Nietzsche en su afirmación del placer. En el mercado, placer y felicidad sólo son comprendidos como antítesis de sufrimiento y amargura. Su sí y su no son fruto del pensamiento que todo lo piensa como división. No puede, por lo tanto, haber decisión sobre la gran medida de la vida cuando se sigue viviendo bajo la «seguridad» del rebaño y el ruido del mercado. El decir-sí debe ser vivido como principio integrador, y esto hace el más solitario de los hombres.

La visión del más solitario de los hombres es relatada en el discurso intitulado «De la visión y el enigma» ${ }^{13}$. En su primera parte, la que hemos traído en esta última citación, nos encontramos con una mejor aclaración de este componente imprescindible para la comprensión del mensaje que propone el tentador al solitario. En él aparece Zaratustra también en su soledad, el que sabe experimentar y vivir de su soledad, una soledad que se aprende en las montañas y en la cercanía respetuosa a sí mismo, a sus animales, a su sombra, e incluso a los hombres, los pequeños y los superiores, aunque a él le parezca «duro que sean necesarias gentes pequeñas» ${ }^{14}$. De la soledad de Zaratustra se puede comprender el hablar desde la más

$13 \mathrm{Z}$, «De la visión y el enigma», 1.

$14 \mathrm{Z}$, «De la virtud empequeñecedora». 


\section{profunda experiencia de sí mismo. Este más solitario - el amigo ${ }^{15}$ de los audaces viajeros, de los que aman el peligro sin reservarse a sí mismos, amigo de los que gozan del crepúsculo- habla él mis- mo, «para todos y para nadie» ${ }^{16}$. Habla del difícil sendero hacia}

15 En el Prólogo de Zaratustra, 4, encontramos a los que son queridos por el maestro del eterno retorno. «Yo amo a quienes no saben vivir de otro modo que hundiéndose en su ocaso, pues ellos son los que pasan al otro lado. Yo amo a los grandes despreciadores, pues ellos son los grandes veneradores, y flechas del anhelo hacia la otra orilla. Yo amo a quienes, para hundirse en su ocaso y sacrificarse, no buscan una razón detrás de las estrellas: sino que se sacrifican a la tierra para que ésta llegue alguna vez a ser del superhombre. Yo amo a quien vive para conocer y quiere conocer para que alguna vez el superhombre viva. Y quiere así su propio ocaso. Yo amo a quien trabaja e inventa para construirle la casa al superhombre y prepara para él la tierra, el animal y la planta: pues quiere así su propio ocaso. Yo amo a quien ama su virtud: pues la virtud es voluntad de ocaso y una flecha del anhelo. Yo amo a quien no reserva para sí ni una gota de espíritu, sino que quiere ser íntegramente el espíritu de su virtud: avanza así en forma de espíritu sobre el puente. Yo amo a quien de su virtud hace su inclinación y su fatalidad: quiere así, por amor a su virtud, seguir viviendo y no seguir viviendo. Yo amo a quien no quiere tener demasiadas virtudes. Una virtud es más virtud que dos, porque es un nudo más fuerte del que se cuelga la fatalidad. Yo amo a aquel cuya alma se prodiga, y no quiere recibir agradecimiento ni devuelve nada: pues él regala siempre y no quiere conservarse a sí mismo. Yo amo a quien se avergüenza cuando el dado, al caer, le da suerte, y entonces se pregunta: ¿acaso soy yo un jugador que hace trampas? - pues quiere perecer. Yo amo a quien delante de sus acciones arroja palabras de oro, y cumple más de lo que promete: pues quiere su ocaso. Yo amo a quien justifica a los hombres del futuro y redime a los del pasado: pues quiere perecer a causa de los hombres del presente. Yo amo a quien castiga a su dios porque ama a su dios: pues tiene que perecer por la cólera de su dios. Yo amo a aquel cuya alma es profunda incluso cuando se le hiere, y que puede perecer a causa de una pequeña vivencia: pasa así de buen grado por el puente. Yo amo a aquel cuya alma está tan llena que se olvida de sí mismo, y todas las cosas están dentro de él: todas las cosas se trasforman así en su ocaso. Yo amo a quien es de espíritu libre y de corazón libre: su cabeza no es así más que las entrañas de su corazón, pero su corazón lo empuja al ocaso. Yo amo a todos aquellos que son como gotas pesadas que caen una a una de la oscura nube suspendida sobre el hombre: ellos anuncian que el rayo viene, y perecen como anunciadores».

16 Véase en el título de la obra: «Así habló Zaratustra - un libro para todos y para nadie». Heidegger comenta esta característica de la obra en el artículo «Quién es el Zaratustra de Nietzsche», publicado en: Conferencias y artículos, trad. Eustaquio Barjau, Barcelona: Ediciones del Serbal 1994, 91-112 pp. Comenta Heidegger: «"Para todos”, es decir, no para todo el mundo en el sentido de para cualquiera. Sino, quiere decir: "para todo hombre en tanto que hombre, para cada uno, siempre y en la medida en que en su esencia deviene para sí mismo digno de ser pensado" (...) y "para nadie", quiere decir: "para nadie de los curiosos que afluyen en masa de todas partes, que lo único que hacen es emborracharse con fragmentos aislados y con sentencias concretas de este libro y que, a ciegas, van dando tumbos en un lenguaje medio cantarín, medio gritón, ahora meditativo, ahora tempestuoso, a menudo de altos vuelos, pero a veces chato y bidimensional, en vez de ponerse en camino hacia el 
arriba ya en la hora crepuscular, habla del caminar cargado del espíritu de la pesadez ${ }^{17}$ que lo arroja hacia los abismos ${ }^{18}$.

El espíritu de la pesadez es el enemigo de la libertad, él nos impide coger el vuelo obligándonos al paso lento por el camino. Sin embargo, es cierto, «el volar no se coge al vuelo!» ${ }^{19}$, y al caminar por abismos y transformaciones, entre ensayos y preguntas, se hace necesario todo tipo de compañías, incluso las más pesadas, las que tornan el camino más difícil. Según este mismo texto al que acabamos de referirnos, el camino no se descubre, sino que cada uno se hace camino, porque no existe el camino. El camino hacia arriba, y el camino hacia abajo son partes que integran el mismo camino que cada uno se hace al vivir y tal es el caminar que nos relata Zaratustra. El caminar del caminante es la figura para mentar la vida y el modo en el que estamos en ella. Es la vida este caminar, es el hombre este caminante, un tránsito, no una meta. Sobre el hombre como tránsito, dice Zaratustra que «el hombre es una cuerda tendida entre el animal y el superhombre, - una cuerda sobre un abismo. Un peligroso pasar al otro lado, un peligroso caminar, un peligroso mirar hacia atrás, un peligroso estremecerse y pararse. La grandeza del hombre está en ser un puente y no una meta: lo que en el hombre se puede amar que es un tránsito y un ocaso» ${ }^{20}$. Cuando este camino es la representación de la vida y el caminar es el modo mismo en que se trata el movimiento de la vida, una vida que por cierto es una pluralidad de caminos y atascos, de alturas y abismos, y que tiene en el caminar su modo de ser en cuanto estar

pensar que está aquí buscando su palabra"».

17 Vid. Z, «Del leer y el escribir»: El espíritu de la pesadez es lo que «hace caer a todas las cosas».

18 El camino, el crepúsculo de más de un sol, la dirección dupla ya son señales del contrapunto de Nietzsche con relación a la metafísica de Platón. En la misma dirección se encuentra el discurso intitulado «Del árbol de la montaña» en el que el elevarse hacia la altura tiene el mismo contrapunto con el profundizar las raíces hacia abajo, hacia la tierra. Éste es el nuevo componente de la enseñanza de Zaratustra: El camino hacia lo alto es el camino hacia lo noble, no necesariamente hacia lo bueno. Y además, el camino hacia lo alto no excluye, sino que, al contrario de los platonismos habidos hasta ahora, es el camino hacia lo más profundo. Estos dos caminos van a encontrarse en el portal del instante -idea que tendremos ocasión de comentar más adelante.

${ }^{19} \mathrm{Z}$, «Del espíritu de la pesadez».

$20 \mathrm{Z}$, «Prólogo», 4. 
en continuo movimiento, el hablar de camino, entre tantos caminos recorridos por Zaratustra a lo largo de las muchas caminatas que son narradas en la obra, tiene precisamente un significado especial. Como ya hemos señalado, el camino hacia arriba nos recuerda el movimiento de liberación que caracteriza el caminar hacia el conocimiento de la verdad y el Bien según la alegoría de la caverna de Platón en la República ${ }^{21}$. Sin embargo, a diferencia de éste, Nietzsche nos recuerda la difícil tarea de tal liberación y el peso que conlleva. Para empezar, pues, por el hecho que el caminar es un ir hacia arriba, pero también un caerse.

Siguiendo el texto que nos sirve como hilo conductor, el subir cargando el espíritu de la pesadez que tira hacia abajo, el enano de Zaratustra, aunque de un compañero se trate (como lo fueron para Nietzsche/Zaratustra, su enano, sus animales, su sombra, los dos reyes, el papa jubilado, los magos, el más feo de los hombres, el mendigo voluntario, sabios y eremitas, nobles y aristócratas, hombres y mujeres, jóvenes y viejos, etc.), no revela el gozar precisamente de un compañero de viaje, sino más bien revela la soledad que puede uno experimentar junto a tal compañía. El texto es testigo de que la soledad de Zaratustra - el que ha aprendido a amar a la vida y al mundo, el que supo crearse el camino hacia el encuentro consigo mismo - es la soledad que es capaz de romper con el yugo opresor de toda carga que impide el paso hacia la libertad y hacia lo ligero. Para esta liberación hace falta el valor propio del guerrero contra toda enfermedad que aprisiona la vida. La cuestión que se presenta, desde la más profunda y sincera afirmación de la soledad es: «iTú! ¡O yo!» ${ }^{22}$. No hay como seguir el camino de la libertad sin tal decisión de romper con todo lo que nos oprime. Para ello se hace necesario el valor. El valor para decidir, el valor para responder, el valor para seguir viviendo.

21 PLATÓN, La República, 514a-518b. Edición castellana de José Manuel Pablón y Manuel Fernández-Galliano, Madrid: Alianza 1990.

${ }^{22} \mathrm{El}$ que en esta primera parte del discurso se elija en primer lugar al otro (¡O tú! ¡O yo!) puede revelar una primera concepción en la elección/decisión hacia la libertad -el momento del león en el camino de las transformaciones del espíritu. En la segunda parte del texto, Zaratustra invierte el orden poniendo al Yo delante del tú (¡O yo! ¡O tú!), lo que comprendemos como la decisión última y fundamental hacia lo libre. 
A lo que Zaratustra llama su valor como «el mejor matador», al final de la primera parte del citado discurso, es a la fortaleza de voluntad que rompe con todo lo que aprisiona. El hombre ha tenido el valor de luchar contra sus animales pero tiene todavía que luchar contra la compasión por el hombre mismo, pues la compasión es el abismo más profundo. En otro discurso decía Zaratustra: «La guerra y el valor han hecho más cosas grandes que el amor al prójimo. No vuestra compasión, sino vuestra valentía es la que ha salvado hasta ahora a quienes se hallaban en peligro» ${ }^{23}$. El valor que enseña el solitario Zaratustra afirma la vida incluso en lo que tiene de abismático y vertiginoso. El valor, en cuanto valor que ataca, mata a la muerte misma afirmando la vida, incluso el sufrimiento y el dolor en ella. «¿Era esto la vida? ¡Bien! ¡Otra vez!». El valor guerrero es lo que enseña y hace posible el amor a la tierra y por ello cada día vivido es un día feliz ${ }^{24}$.

\subsection{El más pesado de los pesos como valor imperativo}

Retomemos el aforismo 341 de La gaya ciencia. Según el citado aforismo, es allí, en la soledad, tal y como la hemos identificado, o sea, como un sentimiento propio de un hombre de valor, que propiamente nos siguen y se expresan los demonios. Si permitimos que hable el texto, preguntamos sobre lo que dice el tentador. ¿Cuál es su proposición? Quizá lo que aquí importe no sea el contenido de lo que se supone una verdad, sino la respuesta que provoca la proposición misma que hace. Lo que ofrece el tentador al hombre solitario es la idea del retorno y con ella la idea de la vida una vez y otra y así eternamente. El contenido de esta demoníaca proposición lo habremos de tratar más adelante. Por ahora, para empezar a cotejar un primer elemento de análisis lancemos una mirada retrospectiva al conjunto de la escena. El hombre está solo con el tentador y desde esta experiencia tiene que reaccionar a una grandiosa afirmación de la vida.

$23 \mathrm{Z}$, «De la guerra y el pueblo guerrero».

${ }^{24}$ Cf. Z, «La canción del noctámbulo». 
La vida, tal como es, retorna. ¿Qué quiere decir este «tal como es»? Es la vida como voluntad de poder. ¿Qué importa el que retorne eternamente la vida como voluntad de poder? Importa la respuesta a este desafío, porque en la respuesta reside todo el secreto de este aforismo. En el responder encontramos la valoración de la vida. El tipo de respuesta está condicionado por el grado de fuerza que uno es capaz de soportar, pues en la respuesta habita la posibilidad o negación de la afirmación de la vida que a su vez está basada en la cantidad de poder que uno es capaz de querer. Al final del mencionado aforismo, surge como evaluación de toda acción el nuevo imperativo: «iLa pregunta ante todas las cosas: “iquieres esto otra vez y aún infinitas veces?" pesaría como peso más pesado sobre todos tus actos! $\mathrm{O}$ ¿cómo necesitarías amarte a ti mismo y a la vida, para no desear nada más que esta última y eterna confirmación y ratificación?». Es la toma de decisión una respuesta al modo como se comprende la vida. El vivirla como castigo y tormento y anhelo de un más allá conlleva una respuesta negativa y conduce al repudio de la propuesta del eterno retorno. El más allá presupone la creencia en algo fuera de la fuerza misma. El vivir este mundo como un tormento es la negación de la vida misma. De ahí que sea necesario el gran amor a sí mismo y a la vida. Son las condiciones de la afirmación del eterno retorno. « ¡Sea vuestro amor a la vida amor a vuestra esperanza más alta: y sea vuestra esperanza más alta el pensamiento más alto de la vida! ${ }^{25}$. El amor a sí mismo y a la vida, el vivirla desde la alegre y creativa acogida del mundo en cuanto mundo, ya no desde ideales, sino desde su naturaleza, es lo que conduce a querer más vida y en ella el pensamiento del retorno como garantía de la oportunidad de su afirmación. Decía Nietzsche de su tarea: «Mi tarea: la deshumanización de la naturaleza y después la naturalización del hombre, una vez que éste haya alcanzado el concepto "puro" de naturaleza» ${ }^{26}$.

Es la acogida de la necesidad (Notwendigkeit), la menesterosidad de más vida como voluntad de poder, lo que define la posibilidad de la afirmación de la vida. 
Cuando no tenéis más que una sola voluntad, y ese viraje de toda necesidad se llama para vosotros necesidad: allí está el origen de vuestra virtud. ¡En verdad ella es un nuevo bien y un nuevo mal! ¡En verdad, es un nuevo y profundo murmullo, y la voz de un nuevo manantial! Poder es esa nueva virtud; un pensamiento dominante es, $\mathrm{y}$, en torno a él, un alma inteligente: un sol de oro y, en torno a él, la serpiente del conocimiento ${ }^{27}$.

No en vano, Nietzsche advierte sobre la mala comprensión de la necesidad: aquí no se trata de una necesidad personal ${ }^{28}$, ni de una necesidad como fin o causalidad ${ }^{29}$, sino como "aparencialidad útil» ${ }^{30}$. «La "necesidad", no en la forma de un poder total, abarcador y dominante, o de un primer motor; menos todavía como necesaria con el fin de posibilitar algo valioso» ${ }^{31}$. Tampoco como «necesidad mecánica», sino como necesidad de creador, ya que «la necesidad no es un estado de cosas, sino una interpretación ${ }^{32}$. El comprender la necesidad como interpretación afirmativa del mundo y no como categoría metafísica, tal como, «sustancia», «objeto», «ser» $\mathrm{O}$ «devenir» ${ }^{33}$, es lo que conduce a Nietzsche a reflexionar de la siguiente manera:

«Si todo es necesario, ¿qué puedo disponer de mis acciones?». El pensamiento y la creencia son un gran peso que presiona sobre ti junto con los demás pesos y más que ellos. ¿Tú dices que la alimentación, el lugar, el aire, la sociedad te cambian y determinan? Ahora bien, tus opiniones lo hacen aún mayormente, pues éstas te determinan a esta alimentación, lugar, aire, sociedad. - Si incorporas el pensamiento de los pensamientos, éste te transformará. La pregunta para todo lo que quieras hacer: «¿Es esto de tal manera que quisiera hacerlo incontables veces?», es éste el mayor de los grandes pesos $^{34}$.

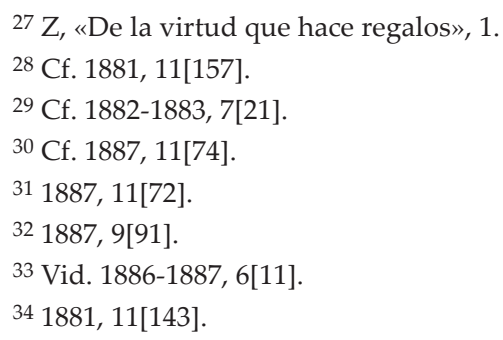


Así, delante de tal confirmación del nuevo imperativo, - el mayor de los grandes pesos, más pesado que los pensamientos, creencias y prejuicios - nos acercamos a nuestro tema. El eterno retorno como imperativo de afirmación de la vida es el que pregunta antes que nada por el ser capaz de querer eternamente lo querido, en fin, querer la vida. Aún en el más duro sufrimiento y dolor poder decir un «así lo quise», es decir, «trasformar todo "fue" en un "así lo quise" - ¡sólo eso sería para mí redención!» ${ }^{35}$.

No nos interesa que pueda o no pueda ser comprobado el pensamiento del eterno retorno en Nietzsche como hipótesis física, ni que haya sido inspirado en culturas ancestrales - orientales y griegas en especial-, o que haya sido incluso gozado en su tiempo de prestigio científico por la mano de algunos estudiosos contemporáneos al propio Nietzsche ${ }^{36}$. El eterno retorno es un pensamiento

35 Z, «De la redención».

36 Agradecemos al Prof. Eloy Rodríguez Navarro el habernos indicado la referencia a la obra de Ofelia Schutte que en la nota número 13 del segundo capítulo de su libro sobre Nietzsche intitulado Más allá del nihilismo. Nietzsche sin máscaras, traducido por el mismo profesor Rodríguez Navarro y publicado por la Editorial Laberinto en 2000, recorre el camino bibliográfico de Nietzsche al elaborar al pensamiento del eterno retorno. Reproducimos aquí la totalidad de la referida nota explicativa: «Nietzsche parece que conocía la obra de dos investigadores principales sobre el principio de conservación de la energía, Friedrich Mohr y J. Robert Mayer. Según Karl Schlechta, en su obra Nietzsche Chronik (Munich 1975, Carl Hanser), uno de los libros que Nietzsche sacó de la biblioteca de Basilea en 1873 fue Allgemeine Theorie der Bewegung und Kraft als Grundlage der Physik und Chemie, de Mohr (Braunschweig 1869). Varios años más tarde (y aproximadamente cuatro meses antes de la aclamada visión de Nietzsche del eterno retorno en el lago Silvaplana, Nietzsche leyó la obra de otro defensor de la conservación de la energía, Julius Robert von Mayer. La nueva edición crítica de las cartas de Nietzsche, recopiladas por G. Colli y M. Montinari, demuestra que Peter Gast (Heinrich Köselitz) estimaba mucho a Mayer y le envió a Nietzsche una copia del libro de éste en abril de 1881 (Nietzsche Briefwechsel. Kritische Gesamtausgabe [KGW], III2, 148 y 158). El ensayo celebrado por Gast, «Dynamik des Himmels», es uno de los varios contenidos en Die Mechanik der Wärme in gesammelten Schriften, de Mayer (Stuttgart 1867, J. G. Cotta). En este libro, Mayer defiende el principio de conservación de la energía y la convertibilidad del calor y la luz en energía. También Mayer relaciona sus opiniones científicas con la visión de una armonía metafísica y cósmica. La respuesta inicial de Nietzsche a la obra de Mayer fue entusiasta y se basaba en la visión de Mayer de la totalidad de la vida y de la energía como una gran armonía cósmica (KGB, III1, 84). Pero un año más tarde, en otra carta a Gast, de marzo de 1882, Nietzsche criticó abiertamente algunas de las tesis defendidas por Mayer (KGB, III1, 183-84). Voy a detenerme brevemente en los desacuerdos de Nietzsche con Mayer. No sabemos hasta que extremo, si es que se dio, Nietzsche estuvo influido por Mohr, cuya obra despertó su atención en 1873. Pero las ideas de Nietzsche tienen 


\section{con relación al cual uno toma la decisión de amar o refutar la vida desde el propio modo como cada cual la vive. La vida es lo que es.}

algunas afinidades con las de un colaborador de Mohr, Ludwig Büchner. Büchner, defensor del materialismo científico, era conocido, entre otras cosas, por popularizar la investigación de Mohr sobre la conservación de la energía en un libro de 1875, titulado «Die Unsterblichkeit der Kraft» (véase Frederick Gregory, Scientific Materialism in Nineteenth Century Germany [Dordrecht 1977, D. Reidel]). Aunque no existe, que yo sepa, ningún dato de que Nietzsche hubiera leído a Büchner, pienso que es revelador citar la reseña de Gregory sobre el libro de Büchner de 1875, para indicar las similitudes entre la popularización de Büchner de la ley de la conservación de la energía y las ideas de Nietzsche sobre la voluntad de poder y el eterno retorno. "[Según Büchner], la naturaleza no ha conocido nunca una parada...; ha sido más bien un ciclo interminable de movimiento que correspondería a diversos tipos de fuerza. Estas fuerzas no podrían ser creadas o destruidas, sino que serían interconvertibles entre sí, de tal manera que su suma es una constante, y la fuerza misma es inmortal... Una fuerza se podría transformar en otra forma, pero la cantidad total de fuerza en el mundo permanecería igual en cantidad" (Gregory, p. 160). Los lectores familiarizados con la visión dionisíaca de Nietzsche de la voluntad de poder recordarán sus palabras: "Este mundo: un monstruo de energía, sin principio, sin fin; una magnitud estable, férrea, de fuerza que no se hace más grande o más pequeña, que no se desgasta, sino que sólo se transforma..." (WM, \& 1067, p. 550 [1885]). Büchner ofreció una explicación de la segunda ley de la termodinámica de una manera que presenta también similitudes con la idea de Nietzsche del eterno retorno. En Licht und Leben (Leipzig 1882), Büchner expresó la ley de la entropía creciente cuando dice que sólo partes del universo morirán, pero que otras partes seguirán viviendo. Después de reconsiderar varias hipótesis cosmológicas sobre la muerte y el renacimiento del sistema solar, Büchner concluía que nuestro mundo «debe celebrar... y celebrará su resurrección algún día» (Gregory, p. 163). La popularización de Büchner de la primera y segunda ley de la termodinámica encaja con la explicación incompleta de Nietzsche de lo que significaría el eterno retorno desde un punto de vista lógico. Las ideas sobre la conservación de la energía y la muerte y el renacimiento del universo estaban muy en el ambiente en la época de Nietzsche. El elemento que Nietzsche añadió fue la idea de que todas las posibles configuraciones de los estados de la energía que se dieron una vez se reproducirán eternamente. El componente ético de la idea (la afirmación total de la vida a pesar de todo el sufrimiento) tuvo también precedentes en el siglo XIX. Schopenhauer se acercó a la articulación de la idea más profunda de Zaratustra en Welt als Wille und Vorstellung (\& 54). Esta obra la descubrió y leyó Nietzsche con entusiasmo en 1865. Después de haber indicado las similitudes entre algunos de los análisis científicos de la conservación de la energía y la teoría de Nietzsche del retorno, yo señalaría también algunas diferencias. Aunque Nietzsche aceptó el concepto de energía, no aceptó el concepto de materia. En marzo de 1882, Nietzsche escribió a Peter Gast diciéndole que Mayer (Mechanik der Wärme) no ha caído en la cuenta de que la materia (Stoffe) es un gran prejuicio (KGB, III3, pp. 183-84). Estos científicos pueden haber tenido datos interesantes; pero, según Nietzsche, están todavía metafísicamente equivocados. Parece que Nietzsche aceptó la idea de la conservación de la energía, pero no identificó a la energía metafísicamente ni con la materia ni con el espíritu. Probablemente dio por sentado que, si elegía una cualquiera de estas dos categorías, quedaba cogido en alguna forma latente, si no explícita, de dualismo». 
El cambio reside en la valoración o interpretación que se le atribuye - el valor. Reconocer el carácter de su necesidad es renunciar a lo que a ella adjuntamos de bueno o malo, la interpretación de la vida que construyamos según nuestra fortaleza o debilidad. El decirsí o decir-no depende del grado de voluntad de poder a que uno está capacitado a responsabilizarse y comprometerse. Del decir-sí o decir-no depende el que el mundo y la vida sean vividos como afirmación o negación, como creación y gran-responsabilidad o encarcelamiento y culpa-castigo-pecado. Es un peso, es decir, una medida, y el mayor, o sea, el que actúa como imperativo (¿categórico?). Por lo tanto, el pensamiento del eterno retorno de lo mismo es la medida con que se establece el valor de la vida misma, el valor del hombre según el quantum de fuerza que puede soportar. El grado de afirmación de la vida y el valor de cada hombre es lo que piensa el peso más pesado.

La relación entre este pensamiento y la caracterización del hombre como aquel que puede hacer promesas, el animal soberano y aristocrático, nos conduce a la afirmación del criterio que justifica la acción en Nietzsche. Lo bueno (en sentido noble y aristocrático) es lo que puede ser querido incontables veces. Lo malo (en sentido esclavo y resentido) es lo que no puede ser querido porque la vida es vista como castigo ${ }^{37}$. Y si recordamos el cántico del Zaratustra, el «De la redención», hemos de identificar lo que es más propio de aquel rechinar de dientes: «"Fue": así se llama el rechinar de dientes y la más solitaria tribulación de la voluntad. Impotente contra lo que está hecho - es la voluntad un malvado espectador para todo lo pasado» ${ }^{38}$. La respuesta al retorno está íntimamente vinculada al modo como se vive y se relaciona con el pasado. Querer la vida es asumir que incluso todo lo pasado fue querido. Se trata de una afirmación global a todo lo que es, sin la cual, de lo contrario, sólo se puede vivir con rencor y rechinar de dientes - el mundo como «valle de lágrimas». La afirmación de una voluntad noble es la afirmación de una voluntad fuerte, creativa y alegre.

37 Para una visión más amplia sobre los conceptos bueno y malo en sentido aristocrático y plebeyo, consultar la primera sección de La genealogía de la moral.

$38 \mathrm{Z}$, «De la redención». 
La vida es este campo de batalla en el que juegan estas dos fuerzas, el decir-sí y el decir-no, a la vez opositoras, a la vez confluentes. Cabe al hombre la decisión de vivir la vida como afirmación o no. De esta decisión se desprenderá todo acontecer y evaluación de su existencia. Este es el eterno juego en el que se juega lo que vale la vida. «iImprimamos la imagen de la eternidad sobre nuestra vida! Este pensamiento contiene más que todas las religiones que desprecian esta vida como fugaz y aún han enseñado acerca de una otra vida indeterminada ${ }^{39}$. El eterno retorno es, por tanto, el pensamiento contrario a todo otro pensamiento que desprecia la vida. La afirmación de la vida sólo es compatible con el querer más vida. Así que, aceptar la doctrina implica, fundamentalmente decir sí a la vida, diciendo sí al mundo y a sí mismo. Sin embargo, para el que prefiera negarla, prefiriendo los trasmundos metafísico-religiosos, no pesa ningún castigo o condenación porque «esta doctrina es indulgente para con los que no creen en ella, no tiene ni infiernos ni amenazas. Quien no cree tiene en su conciencia una vida fugaz» ${ }^{40}$. O sea, la doctrina, aunque sea un pensamiento de afirmación, no niega nada que le sea contrario. No lo niega, sino que lo mira aristocráticamente ${ }^{41}$ como inferior y fugaz.

Los principales negadores del pensamiento del eterno retorno se encuentran entre aquellos metafísicos y sacerdotes de la afirmación del más allá como mundo verdadero. Sin embargo, tal y como se ha vulgarizado la vida en la valoración sacerdotal (metafísico-religiosa) que niega el mundo en función de un más allá, igualmente los ideales modernos afirman la vida como fugaz ${ }^{42}$. Los ideales mo-

$391881,11[159]$

$401881,11[160]$.

${ }^{41}$ La mirada aristocrática a lo malo como inferior esta desarrollada en La genealogía de la moral.

42 1881, 11[163]. «El delirio político que me hace sonreír como en viejos tiempos el frenesí religioso a sus contemporáneos es, ante todo, mundanización, creencia en el mundo, quitarsede-en-mente, "más allá" y "transmundo". Su meta es el bienestar del individuo fugaz: razón por la cual el socialismo es su fruto, i.e. los individuos fugaces quieren conquistar su dicha mediante socialización: no tienen motivo alguno para esperar como los hombres con almas eternas y devenir eterno y futuro devenir-mejor. Mi doctrina reza: la tarea es vivir de tal manera que tenga que desear vivir de nuevo - ¡en cualquier caso lo harás! A quien el empeño le aporte el sentimiento máximo, iqué se empeñe!; a quien el reposo le aporte el sentimiento máximo, ique 
dernos no quieren más que el bienestar. La afirmación de la vida, tal y como se ha definido en el capítulo anterior, no es esta vida ni una vida cualquiera. «Nosotros amamos la vida no porque estemos habituados a vivir, sino porque estamos habituados a amar» ${ }^{43}$. En cuanto voluntad de poder, el concepto de vida y su afirmación contienen una potenciación que lleva el poder a querer el plus de poder. Querer según el pensamiento del retorno, querer la vida, tal y como se está presentando, es potenciar y aumentar la vida misma en todas sus posibilidades. Estamos lejos de confirmar, con el pensamiento del eterno retorno como afirmación de la vida, imperativo vital, la moderna afirmación de las sociedades del bienestar y del progreso o esta modalidad de vivir que conocemos y vivimos ${ }^{44}$.

Además, con el pensamiento del eterno retorno tampoco se trata de aumentar la fuerza, pues, como se ha visto, ésta no aumenta ni disminuye, sino hace crecer lo que de ella depende, la vida misma. En lo que se puede acumular fuerza reside el aumento de poder en la vida. Por ello, es menester no dejar transbordar la fuerza, no desperdiciarla. La imagen que nos ofrece Nietzsche con relación a este especial cuidado de potenciar la fuerza se encuentra en $\mathrm{La}$ gaya ciencia. El modo de no desperdiciar la fuerza debe ser seguido de tal manera que ya no haya más esperanzas últimas o transmundanas, o sea, en todo aquello que ya hemos señalado como lo representado en Nietzsche y que en su filosofía nombra a Dios.

repose!; a quien la subordinación, el secundar, la obediencia le aporten el sentimiento máximo, ¡que obedezca! ¡Sólo que se vuelva consciente de lo que le aporta el sentimiento máximo y no retroceda ante ningún medio! ¡La eternidad está en juego!». También en 1881, 11[172]: «¿Cómo damos peso a la vida interior sin volverla perversa y fanática contra los que piensan distinto? La fe religiosa decrece y el hombre aprende a comprenderse como fugaz y como inesencial, de esta forma se vuelve finalmente débil: no se ejercita tanto en el empeño y el aguante, quiere el goce presente, se hace las cosas fáciles y ligeras -y emplea quizá mucho ingenio en ello».

$43 \mathrm{Z}$, «Del leer y el escribir».

44 Por hacer referencia tan sólo a algunos textos, en especial a los de Zaratustra, podríamos señalar los discursos: «Del árbol de la montaña», «Del nuevo ídolo», «De las moscas del mercado», «El retorno a casa», «De las tablas viejas y nuevas» $\mathrm{y}$ «Del hombre superior». Habría que recorrer una inmensa variedad de textos a lo largo de la obra de Nietzsche si el objetivo fuera desarrollar este importante aspecto. No hay duda de que esto merece la pena y esperamos profundizarlo en el futuro. 
¡Excélsior! — «Nunca más orarás, nunca más adorarás, nunca más descansarás en la confianza infinita - te vedas detenerte ante una sabiduría última, una bondad última, un poder último y desaparejar tus pensamientos - no tienes un guardián y amigo constante para tus siete soledades - vives sin vista a una montaña que tiene nieve en su cumbre y que arde en sus entrañas - ya no hay para ti ningún retribuidor ni perfeccionador último - ya no hay razón en lo que ocurre, ni amor en lo que te ocurrirá para tu corazón, ya no hay abierto ningún lugar de descanso donde tan sólo tenga que encontrar y no buscar, te resistes a cualquier paz última, quieres el eterno retorno de guerra y pazhombre del renunciamiento, ¿quieres renunciar a todo esto? ¿Quién te dará la fuerza para ello? ¡Jamás hombre alguno ha tenido esta fuerza!» - Hay un lago que un día se vedó desaguar y levantó un dique en el sitio donde hasta entonces había desaguado: desde entonces se eleva cada vez más el nivel de este lago. Tal vez precisamente ese renunciamiento nos dará también la fuerza que nos capacitará para soportar el renunciamiento; tal vez el hombre se elevará cada vez más desde el momento en que ya no desemboque en un $\operatorname{dios}^{45}$.

La exigencia para estar en condiciones de acumular la mayor cantidad de fuerza es el concentrarse en la vida misma no haciendo de la vida un tránsito hacia un más allá o un mero reflejo de este trasmundo. El eterno retorno se presenta así, por tanto, como la afirmación de la radical inmanencia. « iNo estar a la expectativa de bienaventuranzas y de bendiciones e indultos lejanos y desconocidos, sino vivir de tal manera que queramos vivir otra vez y queramos vivir así por la eternidad! - Nuestra tarea se nos plantea en cada instante ${ }^{46}$. Pero también, además de ser la afirmación de lo que es, el carácter contingente de la vida, la decisión de querer el eterno retorno es algo que tiene que ser constantemente renovado. La exigencia misma de la decisión siempre retorna, siempre se nos plantea. La afirmación o negación no se hace de una vez para siempre. A lo mejor, en cada acción que se plantea el hombre, a cada instante, se renueva la decisión de afirmar la vida. No hay esperanza en un más allá de la acción, tampoco la hay en una creencia en algo que le sea anterior. El actuar es todo y siempre lo que debe ser querido.

45 GC, 285.

46 1881, 11[161]. Vid. Z, «De los trasmundanos». 
2. Primeras intuiciones sobre el eterno retorno

Para la comprensión del eterno retorno hay que estar abierto a la inclusión de todos los aspectos que disputan el tener poder. Esta doctrina exige un pensamiento capaz de abarcar la pluralidad de las fuerzas que actúan en la totalidad de lo existente. En este pensamiento, todas las polaridades, todas las fuerzas, los errores y los aciertos juegan en el tablero del devenir. Con la imagen del eterno retorno, Nietzsche incorpora todo lo que la tradición filosófica comprendía como irreconciliable. Todo lo que parecía contradictorio a dicha tradición no es más que la expresión de la pluralidad de fuerzas que actúa en todo lo existente, como voluntad de poder.

En un póstumo del año de $1881^{47}$, bajo el título de «El eterno retorno», Nietzsche escribe un proyecto que nos lleva a reconocer algunas intuiciones para comprender el pensamiento más duro. En tanto que imperativo vital, el pensamiento del eterno retorno exige una nueva postura frente al mundo y en ella un nuevo modo de acercamiento a éste. En las tres primeras líneas de dicho póstumo, habla el filósofo de una incorporación: «1. La incorporación de los errores fundamentales. 2. La incorporación de las pasiones. 3. La incorporación del saber y del saber que renuncia (pasión del conocimiento)». De por sí, la expresión «incorporación» ya es reveladora de un nuevo talante. El primero de estos aspectos nos hace recordar al convaleciente (Der Genesende) Zaratustra ${ }^{48}$ cuando tiene que reconocer que incluso lo más pequeño tiene que regresar. Con ello lo más pequeño, e incluso los grandes errores. Todo lo que fue considerado equivocado por el filósofo, por ejemplo, en el campo de la moral, acaba por ser reconocido como útil en algún aspecto para la historia de la humanidad. No obstante, el reconocimiento de los errores o su incorporación no invalidan la crítica misma de tales equivocaciones. Mientras, la incorporación apunta al carácter fundamentalmente plural de los elementos que componen la realidad y, como tal, este pensamiento que incorpora los errores, es 
fruto de una reflexión de madurez del filósofo, para el que es necesaria la gran enfermedad y la mayor de todas las convalecencias.

Y de alguna manera retomando lo que venimos afirmando, es de esperar que a la hora de concebir su pensamiento más amplio se integren en él elementos tales como las pasiones y la pasión del conocimiento. Otro punto importante en esta consideración es la no-concepción del hombre como fin, sino como tránsito. La vida no es valorada desde la centralidad antropológica que la tradición filosófica, teológica y científica concedieron al hombre. Más que un individuo, el hombre es visto como un ser integrado al mundo, como parte suya, como parte del todo, el hombre sufre el mismo movimiento de todo lo existente: degradación y debilitamiento.

Tales consideraciones conducen al postulado metodológico necesario al pensamiento del eterno retorno que comprende, según Nietzsche: la asimilación de la pluralidad de fuerzas que actúan en lo real, el comprender el mundo como devenir, el incorporar el hombre en la totalidad de la vida - por lo tanto, negarlo en cuanto mero individuo, y por fin, el ver el mundo desde muchos ojos. En todo ello actúa la pasión del conocimiento en el hombre que en su tarea frente a la nueva doctrina debe vivir la vida «en impulsos y ocupaciones», estar totalmente entregado y abandonado a ella para después crearse ojos observadores y mantener «los impulsos como fundamento de todo conocer». Vivir y conocer suponen incorporación de saber y verdad, error y pasión. La fuerza que mueve la vida se alimenta de la lucha de estos elementos. Por eso, incorporadas estas primeras consideraciones, se llega a comprender el eterno retorno como la medida para el saber, el errar y las costumbres. El eterno retorno, en cuanto nuevo imperativo regulador de la acción, se presenta como el conocimiento por excelencia, el conocimiento más esencial, pensamiento abismático y al mismo tiempo mucho más elevado que las cosas humanas. Por tanto, se hace necesario el pathos del conocimiento que integra razón y pasión, verdad y error.

El pensamiento del eterno retorno no concibe ninguna compasión por lo pasado, por la muerte o el dolor. Esta doctrina más bien acoge el carácter trágico de la existencia y del mundo. Por ello, la nueva mirada del sabio se hace con indiferencia y contemplación. 
Tales son las posibilidades del seguir viviendo. En la afirmación de la vida según el pensamiento del retorno eterno todo tiene que seguir repitiéndose eternamente y nada se puede hacer para contener este movimiento.

En el referido texto, Zaratustra se presenta como el abogado de la vida, del sufrimiento y del círculo - es su autodefinición. En ello encontramos los elementos suficientes para fundar nuestra argumentación que presenta el eterno retorno como el pensamiento que redime al mundo y al hombre de la conciencia de culpa y pecado, la que a su vez estructura el modo por el que se ha erigido la metafísica, la moral y la religión como negación de la vida y búsqueda de sentido para el sufrimiento desde la creencia en los trasmundos.

Vida, si cabe insistir, es una realidad que, en Nietzsche, no está dividida entre real y aparente, sino que es una realidad que engloba la totalidad de lo existente como gozo y sufrimiento, afirmación y negación, bueno y malo. El concepto de vida utilizado por Nietzsche es fundamentalmente un concepto trágico, es decir, no se oculta bajo las máscaras de una idealidad del bien que niega el mal, incierto y doloroso. Tampoco es pesimista y negador, sino, más bien al contrario, es afirmador de la vida. Nietzsche en su vida, en su personaje principal -Zaratustra-, en todos los personajes secundarios (sus sombras) y en sus «tipos», se revela a sí mismo en su enfermedad, su dolor, su convalecencia y su alegría en la vida. Las intuiciones de su pensamiento, antes de ser una teoría, una moral o una metafísica, fueron vivenciadas. Pero, desde tal vivencia nos ofrece uno de los más bellos testimonios de cómo se puede amar profundamente la vida desde el más hondo dolor y de cómo lo que se hizo a lo largo de la historia de la moral, de la metafísica y de la religión fue justamente lo contrario. Nietzsche vivió filosóficamente su existencia y nos habla desde esta experiencia. Con ella abre camino a un nuevo filosofar cuya meta no es un más allá de los ídolos, la verdad, la cosa en sí, sino un filosofar que se ocupa de lo cercano y fundamental que es el mundo, la vida misma. El pensar la vida no como un pasado, sino como proyecto. Por eso insiste en el crear como redención de la voluntad. Por eso se preocupa por el país de los hijos, ya no el país de nuestros padres. «El país de vuestros hijos es el que debéis amar: sea ese amor vuestra nueva 
nobleza, _ ¡el país no descubierto, situado en el mar más remoto! ¡A vuestras velas ordeno que partan una y otra vez en su búsqueda! En vuestros hijos debéis reparar el ser vosotros hijos de vuestros padres: ¡así debéis redimir todo lo pasado!» ${ }^{49}$.

Zaratustra convaleciente es la redención de la enfermedad del pasado y de toda metafísica y moral dualistas, en realidad, una sola enfermedad, la que niega el mundo y a sí mismo. La enfermedad que ha creado toda valoración pesimista y débil. El convaleciente tiene como primera intuición la comprensión de la necesidad de todas las fuerzas que componen el jardín que es el mundo. En este jardín habita lo grande y lo pequeño - ésta es la verdad del mundo. Además, todo vuelve - eternamente. Volver es el estar en movimiento de todas las fuerzas que componen este mundo: «eternamente rueda la rueda del ser». El mundo no es una realidad estática y fijada, en él «todo muere, todo vuelve a florecer», esta es la nueva comprensión del ser: el devenir. ¿Cómo volver el mundo bello? Con los sonidos y las palabras. Con ellos «el hombre baila sobre todas las cosas». Pero con las palabras puede el hombre crear puentes tanto como maldecir y acusar a la vida. Por ello, jojo!, más que hablar el pensamiento del eterno retorno es un canto, un canto a la vida.

El canto del retorno no quiere una vida nueva o mejor, sino «esta vida misma e idéntica vida, en lo más grande y también en lo más pequeño». Este canto, un nuevo camino y un nuevo modo de hablar ${ }^{50}$, sólo puede ser un camino, un canto y el modo de ser del guerrero y de la lucha - los nombres de lo libre y de la libertad en Nietzsche. El juego de la lucha entre las voluntades de poder es la letra de este cantar: «Todo se rompe, todo se recompone; eternamente se construye a sí misma la misma casa del ser. Todo se despide, todo vuelve a saludarse; eternamente permanece fiel a sí el anillo del ser». Esta lucha nada tiene que ver con idealidades metafísicas, pues, «en cada instante comienza el ser; en torno a todo "Aquí" gira la esfera "Allá". El centro está en todas partes. Curvo es

49 Z, «De tablas viejas y nuevas». Véase también: «Del país de la cultura», «De la bienaventuranza no querida», «Del hombre superior», «El signo».

${ }^{50} \mathrm{Cf} . \mathrm{Z}$, «El niño del espejo». 
el sendero de la eternidad». Por ello recordamos ahora la segunda parte de aquel discurso que citamos en la primera parte, en el momento de explicitar la importancia de la soledad, en el momento de comprender el cuándo y el modo en que se revela la cuestión decisiva. El texto es «De la visión y el enigma» ${ }^{51}$, que revela «la visión del más solitario». En su segunda parte, la que citamos por separado, hay dos elementos que se complementan. Uno de ellos es propiamente la afirmación de la doctrina, el enigma, y el segundo la imagen del hombre que es estrangulado por la serpiente, la visión. La visión, el enigma. ¿Qué pueden tener en común? Tal es la pregunta que nos guía, en la cual más bien nos movemos. Zaratustra se libera del enano, con un « ¡Yo! ¡O tú!». Es la decisión última y fundamental. La opción primera es por la afirmación de sí mismo. Enseguida, le revela su pensamiento más abismal. El camino por el que parece haber un hacia arriba y un hacia abajo se revela en la descripción de Zaratustra como un camino único en el que en cada momento se encuentran todo el pasado y todo el futuro. El portal más bien no es un puerto de llegada, al que se acerca después de un largo caminar, no es el marco de un bien finalista, sino que es un punto de encuentro en el camino. La imagen del portal no marca ni el principio ni la meta y rompe por lo tanto con la antigua imagen del camino que tiene como fin el soleado bien, el desembocar en $\operatorname{Dios}^{52}$.

La visión de Zaratustra ${ }^{53}$, revela y desvela al hombre que pudiera estar dormido ${ }^{54}$, el hombre que prefiere elegir un sinsentido, la nada, antes que carecer de una meta ${ }^{55}$. El dormir del hombre, en cuanto la más alta virtud, es el modo propio de ser y vivir la vida bajo la enseñanza de las cátedras de los sabios pregoneros de la renuncia y del dualismo moral y metafísico. Estos sabios, del tipo sacerdotal en la filosofía y en la religión, ignoran la verdad extramoral, es decir, la verdad del mundo más allá del bien y del mal.

$51 \mathrm{Z}$, «De la visión y el enigma», 2.

52 Véase de nuevo el aforismo GC, 285 citado más arriba.

53 Véase en $\mathrm{Z}$, «El convaleciente»: «Yo le mordí la cabeza y la escupí lejos de mí».

54 Vid. Z, «De las cátedras de la virtud».

55 Cf. GM, III, 28. 
La sabiduría de los somnolientos hace que los hombres se sientan reconfortados en la presunción del saber lo bueno y lo malvado ${ }^{56}$. Pero este saber estrangula. Su símbolo es la serpiente. ¿Qué es la serpiente? En la visión de Zaratustra, la serpiente es lo que estrangula y puede llegar incluso a matar. Entre todo lo que puede ser estrangulador del hombre nos interesa el «estrangulador llamado “pecado" $\gg{ }^{57}$. Además, la serpiente es también la imagen que aparece en la configuración matricial de la historia de la culpa y del pecado en nuestra civilización ${ }^{58}$. ¿Estaría Nietzsche pensando en ello? Lo cierto es que tal y como lo leemos no hay elementos que se lo impidan. Y siendo así, ¿qué significa la victoria sobre la serpiente? A lo que responde Zaratustra: «Los buenos y justos me llaman el aniquilador de la moral: mi historia es inmoral» ${ }^{59}$. Su inmoralidad es fundamentalmente ateísmo ${ }^{60}$ contra los ídolos de la verdad enseñada por los «sacerdotes». Romper con la serpiente es romper con el mayor peligro para el futuro de los hombres, romper con los

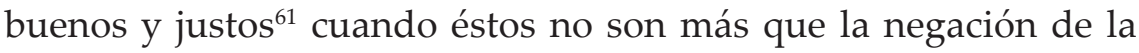
afirmación creadora $^{62}$. O sea, romper con la historia de la moralización del mundo que impregnó la metafísica y la religión del más negativo sentido de culpabilidad.

El romper con la estructura de la culpabilidad, al romperse con la serpiente estranguladora es la mayor liberación. El que estaba tumbado se pone en pie de un salto, un salto a lo libre, "pero no como un angustiado que busca aire, sino más bien como un vidente y cantor ${ }^{63}$. El portador de una nueva felicidad, una nueva libertad y una nueva sabiduría. Contra lo estrangulador, lo ligero que salta, contra la pesadez y la culpa, la libertad y lo libre. Dejemos de lado

56 Cf. Z, «De tablas viejas y nuevas», 2.

$57 \mathrm{Z}$, «Del gran anhelo».

58 Cf. Génesis, 1 y 2.

${ }^{59} \mathrm{Z}$, «De la picadura de la víbora».

$60 \mathrm{Z}$, «De la virtud empequeñecedora»: «Zaratustra es ateo».

${ }^{61}$ Cf. Z, «De las tablas viejas y nuevas».

62 Véase en el discurso de Zaratustra, el intitulado «Del gran anhelo», el variado abanico de posibilidades de significación de la liberación de todo lo estrangulador, además del ya citado pecado.

${ }^{63} \mathrm{Z}$, «El niño del espejo». 
por un momento el estudio de este rico texto, uno de los que más claro nos parece relacionar la visión de la afirmación de la vida en la doctrina del eterno retorno como redención de la culpa, para detenernos en un otro pasaje igualmente importante. Para combatir el espíritu de la pesadez, el estrangulador, el símbolo de la negación de la vida, enseña Zaratustra:

Y también a mí, que soy bueno con la vida, paréceme que quienes más saben de felicidad son las mariposas y las burbujas de jabón, y todo lo que entre los hombres es de su misma especie. Ver revolotear esas almitas ligeras, locas, encantadoras, volubles - eso hace llorar y cantar a Zaratustra. Yo no creería más que en un dios que supiese bailar. Y cuando vi a mi demonio lo encontré serio, grave, profundo, solemne: era el espíritu de la pesadez, -él hace caer a todas las cosas. No con cólera, sino con la risa se mata. ¡Adelante, matemos al espíritu de la pesadez! He aprendido a andar: desde entonces me dedico a correr. He aprendido a volar: desde entonces no quiero ser empujado para moverme de un sitio. Ahora soy ligero, ahora vuelo, ahora me veo a mí mismo por debajo de mí, ahora un dios baila a través de mírt

\section{Fuerza y devenir en el eterno retorno}

Hemos destacado algunos de los principales argumentos entre los discursos de Zaratustra y algunos de los póstumos de Nietzsche que deben considerarse cuando se quiere pensar el peso más pesado. En breves líneas traeremos a colación otras referencias al tiempo que vamos creando y dejando paso a la comprensión e importancia de tal reflexión.

${ }^{64} \mathrm{Z}$, «Del leer y el escribir». Hemos cambiado la traducción siguiendo la orientación del profesor Navarro Cordón en su seminario sobre Zaratustra: «ahora un dios baila por medio de mí» - jetzt tanzt ein Gott durch mich = ahora un dios baila a través mío/atravesándome. 


\subsection{El mundo de la fuerza}

Nietzsche considera que el mundo de la fuerza, según otro póstumo del mismo año $1881^{65}$, no sufre ninguna reducción. Si así fuera, al transcurrir el tiempo se volvería cada vez más débil. Sin embargo, la fuerza sigue siempre la misma, lo que no significa que llegue alguna vez a equilibrarse. No hay ni equilibrio, ni reposo. La fuerza es igualmente grande y móvil. La fuerza es la misma siempre, eternamente. Ni aumenta, ni disminuye. En cuanto cantidad finita (como los granos en el reloj de arena) gira eternamente sin gastarse. Tal consideración nos conduce al pensamiento de que el eterno retorno es la toma de consciencia de esta realidad que es la fuerza en eterno movimiento, o mejor dicho, la vida en eterno devenir. Esta cantidad de fuerzas son eternamente existentes y están eternamente en movimiento. Las circunstancias generadas por estas fuerzas en movimiento son instantes configurados por su modo propio de estar a cada momento. Considerando que el nombre para esta fuerza haya sido concebido por Nietzsche como voluntad de poder, el mismo que nombra la vida, es forzoso comprender que la afirmación de lo que es, es decir, lo inmanente en la vida misma, es esta cantidad limitada de fuerzas en eterno movimiento. Ser capaz de comprender este elemento más interior que es la afirmación de la vida nos libera del malentendido del enano que comprende el retorno como la repetición circular de todo acontecer fáctico. En Nietzsche, por la boca de su Zaratustra, la afirmación del retorno es siempre la afirmación de este algo interior a lo que su filosofía llama la voluntad de poder. La voluntad de poder se consume sin agotarse jamás. Lo que es, o sea, dolor, placer, error, acierto, el mundo, la vida, brilla siempre de nuevo porque es un modo propio de ser de la fuerza en cuanto voluntad de poder.

Negar la vida, el modo propio de estar en el mundo de la conciencia culpable, enfermiza y deudora, es negar, en su esencia, el juego que tiene este tirar a los dados que en cada movimiento del devenir se juega. Pero, ¿es que en cada jugada puede surgir algo 
que sea nuevo? ¿O acaso existen posibilidades infinitas de combinación de cada grano de este reloj de arena que es el mundo? Esta es la claridad más grande, la hora del mediodía: «todo devenir se mueve en la repetición de un determinado número de estados completamente iguales», conforme lo desarrollado en cita anterior.

\subsection{No hay un devenir nuevo, el mundo no tiene una meta}

Por lo tanto, tal y como estamos siguiendo el pensamiento del eterno retorno, no hay un devenir nuevo, sino el devenir del mismo en un movimiento que es eterno, una vez que hay una cantidad limitada de fuerza y una determinada cantidad de posibilidades de configuración entre ellas que se articulan eternamente. Tal y como nos dice Nietzsche, «el devenir infinitamente nuevo es una contradicción: supondría una fuerza infinitamente creciente» ${ }^{66}$. Junto a ello, en conformidad con lo dicho en el aforismo 109 de La gaya ciencia, se debe tener cuidado y no atribuir a este ciclo una valoración humanizadora. Hay que deshumanizar el devenir, o sea, volver a naturalizarlo liberándolo de las atribuciones, interpretaciones y valoraciones humanas, hay que liberarlo de la configuración en la que le ha metido el «y». En contra de la interpretación según la cual se considera el mundo como portador de una ley, una razón, una meta, que considera igualmente el mundo engendrando siempre algo nuevo, este sentido humano, demasiado humano, sin el que no seríamos capaces de orientarnos, afirma Nietzsche:

Cuidémonos de atribuir a este ciclo cualquier afán, meta: o de valorarlo de acuerdo a nuestras necesidades como tedioso, estúpido, etc. En él se da, en efecto, el máximo grado de sinrazón tanto como lo contrario: pero no se puede medir de acuerdo a esto; razonabilidad o

66 1881, 11[213]. Nietzsche desconoce las leyes motrices internas del ser orgánico Vid. 1884, 26[81]. «Hasta ahora no tenemos la menor idea de las leyes motrices internas del ser orgánico. La "figura" es un fenómeno óptico: haciendo abstracción de los ojos, un sinsentido». De nuestra parte no es que quedaría pendiente una investigación más profundizada sobre el tema de la investigación de tales leyes junto al desarrollo científico contemporáneo, sino que siguiendo a Nietzsche no hay la posibilidad de que tales leyes existan. 
irrazonabilidad no son ningún predicado para el todo. - Cuidémonos de pensar la ley de este círculo como devenida según la falsa analogía del movimiento circular dentro del anillo: no hubo primero un caos y después gradualmente un movimiento más armónico y, por último, un movimiento fijo, circular de todas las fuerzas: antes bien, todo es eterno, no devenido: si hubo un caos de las fuerzas entonces el caos era también eterno y retornaba en cada anillo. El ciclo no es algo que ha devenido, él es la ley primigenia (Urgesetz), tal como la magnitud de energía (Kraftmenge) es ley primigenia, sin excepción, ni transgresión. Todo devenir ocurre dentro del ciclo y dentro de la magnitud de energía; no utilizar, pues, para la caracterización del ciclo eterno los ciclos que devienen y pasan, v.gr. los de los astros o el flujo y reflujo, día y noche, las estaciones ${ }^{67}$.

La ley no es nada que sea un conductor hacia una finalidad ${ }^{68}$. En el caso de que sea posible hablar de ley, no se trata de una ley para el movimiento, sino de una ley primigenia (Urgesetz) que es el movimiento mismo: movimiento dentro del ciclo y dentro de la cantidad de fuerza. Lo que se afirma, por tanto, no es la finalidad, sino el movimiento del devenir que es constante y por ello siempre retorna (porque es constante y porque la cantidad de fuerza es siempre igual). Hay que considerar la importancia de la advertencia de Nietzsche para no tomar lo que deviene y pasa como caracterización del ciclo eterno.

67 1881, 11[157]. Siguiendo la traducción de Chover Kraftmenge aparece como «magnitud de energía». Véase en la Antología organizada por J. B. Llinares Chover y G. A. Meléndez Acuña. Utilizamos esta traducción en las citas de este texto.

68 1882-1883, 7[21]: «Se alcanza algo necesariamente: ipero un saber de ello es imposible, así pues también un saber previo! Es aspecto más importante: alcanzar la inocencia del devenir excluyendo los fines. Necesidad, causalidad, ¡nada más! ¡Y tildar de mendaz a todo aquello que habla de «fines» y donde siempre hay sólo un resultado necesario! La historia jamás puede demostrar "los fines": pues lo único que está claro es lo que han querido pueblos e individuos, siempre algo esencialmente distinto a lo que se alcanzó. En pocas palabras, todo lo alcanzado e, con respecto a lo querido, absolutamente incongruente (por ejemplo, masticar como "intención" y "acción"). La historia de las "intenciones" es cosa bien distinta que la historia de los "hechos" en la moral. Es el prejuicio más común, el que de la acción no ve más que lo que ella coincide con el fin intencionado. Es esta fijación por los fines una señal del nivel bajísimo del intelecto - ¡Todo lo esencial, la acción misma y el resultado se pasan por alto!». 
Así como reconoce que no hay un devenir nuevo, Nietzsche afirma que el mundo, en cuanto fuerza, tampoco tiene ninguna meta $^{69}$. Si existiese tendría que haberse alcanzado aunque fuera un estado final inintencionado. También están refutados el carácter de perduración, de inmovilidad y de «ser». Si tuviese la capacidad de ser, sigue Nietzsche, se habría llegado al término de todo devenir, de todo pensar, de todo «espíritu» ${ }^{70}$. El mundo, por tanto, es incapaz de ser, no tiene ni meta ni algún estado final. Sin embargo, este pensamiento es tan difícil como librarse de los prejuicios respecto a todo acontecer y de la costumbre de tener a Dios como conductor y creador del mundo. Por eso, puede ser que incluso en la falta de meta se prefiera seguir buscando una intención y una finalidad. En el fondo, lo que se busca es afirmar el carácter novedoso de todo devenir, reconociendo al mundo como infinita reconfiguración de sus formas y situaciones. Pero, el mundo no es ni infinito ni se asemeja al viejo Dios creador. Esta forma de creer el mundo como semejante a Dios es resultado del ateísmo incompleto. Para Nietzsche, se debe negar que el mundo tenga un carácter ilimitado en cuanto es reconocido como fuerza, es decir, como voluntad de poder.

Dos años más tarde, el filósofo repite la misma idea. Tampoco el movimiento del mundo sigue una meta ${ }^{71}$. Si la hubiera, estaría alcanzada y realizada. Al contrario, este aforismo, el número 11[72] del año de 1887, destaca la necesidad de explicar el devenir sin recurrir a estas nociones de meta, intención o finalidad. Para Nietzsche, «el devenir debe aparecer justificado en todo momento», es decir, cada instante trae consigo la totalidad del devenir. Tal afirmación de la inmanencia de todo devenir conduce a la negación de Dios como su conciencia integral y primer motor. En esta hipótesis, la idea de Dios es la más alta negación del devenir. La consideración de la existencia del ente conduce a dicha desvalorización del

${ }^{69}$ Cf. 1885, 36[15].

${ }^{70}$ Quizá sería oportuno en este momento establecer un diálogo con Hegel. Sin embargo, no es este nuestro objetivo ahora, lo que nos condiciona el tema y el límite de esta investigación. Queda abierta la posibilidad de, en el futuro, retomar este hilo del debate de Nietzsche con Hegel.

${ }^{71}$ Cf. 1887, 11[72]. 
devenir como superfluo y carente de sentido. La hipótesis de la existencia del ente en cuanto fuente de toda difamación del mundo reposa sobre los juicios de valor que considera como " "el mundo mejor", el mundo verdadero, el mundo del "más allá", "la cosa en sí"». En resumen, nos revela el aforismo:

1. el devenir no tiene un estado que sea su meta, no desemboca en un «ser».

2. el devenir no es un estado aparente; quizá el mundo del ente es una apariencia.

3. el devenir tiene el mismo valor en todo instante: la suma de su valor se mantiene igual: dicho de otra manera: no tiene ningún valor, puesto que falta aquello con que se lo podría medir y en relación con lo cual la palabra «valor» tuviese sentido ${ }^{72}$.

Con ello ya estamos en condiciones de llegar a una consideración acerca de la doctrina del eterno retorno. Vamos ahora a dar un paso más recogiendo todos estos puntos que están siendo señalados en el horizonte de la interpretación de la doctrina del eterno retorno como doctrina de la redención de la culpa. Dediquémonos a una formulación más amplia del pensamiento del eterno retorno, aunque reconozcamos que, en primer lugar, este pensamiento mismo tiene en Nietzsche un carácter de hipótesis y, en segundo lugar, es el pensamiento del eterno retorno una doctrina que tiene que madurar ${ }^{73}$.

Hasta aquí nos hemos dedicado fundamentalmente a la doctrina del eterno retorno, o sea, a la afirmación de la fuerza como realidad finita que no atiende a ninguna meta y que, sin embargo, retorna eternamente en un tiempo infinito. Nietzsche poseía, en aquel año de 1881, la siguiente configuración de su pensamiento capital:

72 1887, 11[72].

73 1881, 11[158]: «iCuidémonos de enseñar esta doctrina como una religión repentina! Ella debe permear lentamente, generaciones enteras han de trabajar en ella y en ella hacerse fértiles, - para que se convierta en un gran árbol que dé sombra a toda la humanidad del porvenir. ¡Qué son el par de siglos en los que el cristianismo se ha mantenido! ¡Para el pensamiento más poderoso se requieren muchos siglos - por mucho, mucho tiempo ha de ser pequeño e impotente!». 
La magnitud de toda fuerza está determinada, no es nada «infinito»: ¡cuidémonos de estas extralimitaciones del concepto! En consecuencia, el número de las situaciones, cambios, combinaciones y desarrollos de esta fuerza es, sin duda, inmensamente grande y a la vez prácticamente «inconmensurable», pero, en todo caso, determinado y no infinito. Pero el tiempo, en el que el universo ejerce su fuerza ciertamente es infinito, i.e., la fuerza es eternamente igual y eternamente activa: - hasta este instante ha transcurrido ya una eternidad, i.e., todos los desarrollos posibles tienen que haber existido ya. Por lo tanto, el desarrollo presente tiene que ser una repetición y así también en el que lo engendró y el que surge de él y así sucesivamente hacia adelante y hacia atrás. Todo ha existido innumerables veces en la medida en que la situación total de todas las fuerzas retorna siempre. $\mathrm{Si}$, descontando esto, algo igual ha existido alguna vez o no, es algo totalmente indemostrable. Parece que la situación total conforma novedosamente las propiedades hasta en lo más mínimo, de suerte que dos situaciones totales diferentes no pueden tener nada igual. ¿Puede o no haber algo igual en una única situación total, v.gr. dos hojas? Lo dudo: esto supondría que tendrían un origen absolutamente idéntico y entonces tendríamos que asumir que ha existido algo idéntico por toda la eternidad anterior, a pesar de todos los cambios en las situaciones totales y toda creación de nuevas propiedades - ¡una asunción imposible! $!^{74}$

Concluyendo, tal como venimos señalando en otros aforismos, se confirma la teoría de la fuerza como realidad determinada y finita. Aunque el número de las situaciones y combinaciones de la fuerza sea muy grande, casi inconmensurable, obedecen dichas conformaciones de la fuerza a una cantidad limitada de posibilidades. Pero, con relación al tiempo ${ }^{75}$, en que actúa dicha fuerza, este sí que es infinito. Por consiguiente, concluye Nietzsche, todo instante transcurre eternamente, «la fuerza es eternamente igual y eternamente activa», o sea, «todos los desarrollos posibles tienen que

$741881,11[202]$.

75 Sobre el tiempo en la filosofía de Nietzsche nos remitimos a la obra de Juan Luis Vermal, La crítica de la metafísica en Nietzsche. Reconstruyendo el tema a lo largo de la obra del filósofo, destacaríamos, para lo que se investiga en este estudio, la segunda parte de la obra en especial los tres últimos capítulos. 
haber existido ya», leemos en el aforismo. "Alles ist unzählige Male dagewesen, insofern die Gesammtlage alles Kräfte immer wiederkehrt». (Todo ha existido innumerables veces en la medida en que la situación total de todas las fuerzas retorna siempre). El eterno retorno es la pura afirmación de la inmanencia del mundo. La situación total habla de lo más interior y diverso (es decir, plural) que actúa en todas las cosas, la fuerza en cuanto voluntad de poder. Por lo tanto, el eterno retorno es la afirmación de la fuerza en cuanto voluntad de poder, finita y determinada, que retorna siempre. No aumenta ni disminuye, pues es siempre y eternamente la misma. La situación total en cuanto voluntad de poder es igual siempre, activa siempre. La fuerza (voluntad de poder) es este mismo y plural que retorna siempre.

Para Nietzsche, esta es la condición para imprimir al devenir el carácter del ser. Fuera de esta hipótesis no hay posibilidad para el ser. La posibilidad del ser es el devenir constante y eterno del mismo. No hay algo nuevo, ni meta más allá de la realidad inmanente. Contra toda concepción que comprende un fundamento en el más allá, un Dios, un ser, una cosa en sí, un mundo verdadero, Nietzsche antepone el pensamiento del retorno como hipótesis. El que el pensamiento mismo esté por «demostrarse», si se quiere buscar justificantes según el canon de la ciencia, no es lo que importa. Se trata de comprender el pensamiento del eterno retorno como imago mundi, según el cual las fuerzas se encuentran en continua disputa aunque estén plenamente integradas, pero jamás en equilibrio o reposo. El mundo es una unidad provisional de fuerzas diversas, pero determinadas y finitas que están en constante acción y relación, son eternamente activas.

Este pensamiento exigente del eterno retorno, esta imago mundi en cuanto nueva metáfora del mundo, nueva con relación a las viejas y conocidas valoraciones morales y metafísicas, pide una total entrega a lo que conforma la vida, o sea, a la voluntad de poder. En esta entrega rompemos con toda finalidad o meta, con toda culpa referente a un origen, causa, mundo verdadero o cosa en sí. Lo que tenemos ahora es la tierra como sentido. No hay más ninguna idealidad, ninguna compasión, sino el amor fati del que el eterno retorno es la expresión más acabada. No se trata de una entrega 
maquinal o demoledora, sino presencia poética y creadora. Sólo poéticamente puede el hombre comprender al eterno retorno. De suerte que así puede sentirse parte del todo, integrado al conjunto de las fuerzas en movimiento. De hecho, el hombre habita la tierra como un artista creador. Tal modo de ser artista se asemeja al peculiar modo de ser de los niños: están entregados al juego de las fuerzas que luchan inocentes y libremente al paso que se saben parte de él. No tenemos ningún mérito que nos haga distintos de todo lo vivo, nos enseña este pensamiento. Quizá, lo que nos distinga sea la capacidad que desarrollamos para sabernos en este juego. Lo que nos capacita para él es la razón, ella misma fruto de este movimiento de la vida como un instrumento construido por ella, y de la misma manera, los sentidos. Con esta totalidad perceptiva miramos al instante e inmediatamente y al mismo tiempo en que el instante es percibido, seguimos en el juego. Cada momento o instante percibido por la razón y los sentidos es una perspectiva posible desde el múltiple pero limitado juego de las fuerzas en sus inconmensurables relaciones, situaciones o cambios. Toda perspectiva de la percepción será provisional y limitada, un castillo de arena, ya que el movimiento eterno de las fuerzas es un construir, demoler y reconstruir. No hay nada que sea duradero, a no ser el juego mismo del devenir eterno. En este juego, las cosas están lanzadas al mismo tiempo que se lanzan ellas mismas. Papel singular tiene el hombre en este juego. Es uno más, pero es quien puede decir lo que pasa. Su decir es siempre la perspectiva de una determinada configuración de las fuerzas, habla desde la posibilidad de tal determinación. Tal es su libertad. La libertad como esta batalla de fuerzas finitas, pero en un juego eterno. Jamás libertad infinita, dado que las fuerzas múltiples y distintas, buscando sobreponerse unas a las otras obedecen a su carácter limitado y finito. Y, en el pensamiento de Nietzsche no puede haber nada más allá de la afirmación de la vida en cuanto este conjunto de fuerzas en eterno movimiento. La apertura de la libertad es el eterno repetirse de las posibilidades finitas. 


\section{Para vivir el eterno retorno}

Quien, como yo, se ha esforzado durante largo tiempo, con cierto afán enigmático, por pensar a fondo el pesimismo y por redimirlo de la estrechez y simpleza mitad cristianas mitad alemanas con que ha acabado presentándose a este siglo, a saber, en la figura de la filosofía schopenhaueriana; quien ha escrutado realmente, con ojos asiáticos y superasiáticos, el interior y la hondura del modo de pensar más negador del mundo entre todos los modos posibles de pensar $-\mathrm{y}$ ha hecho esto desde más allá del bien y del mal, y ya no, como Buda y Schopenhauer, bajo el hechizo y la ilusión de la moral, -quizá ése, justo por ello, sin que él lo quisiera propiamente, ha abierto sus ojos para ver el ideal opuesto: el ideal del hombre totalmente petulante, totalmente lleno de vida y totalmente afirmador del mundo, hombre que no sólo ha aprendido a resignarse y a soportar todo aquello que ha sido y es, sino que quiere volver a tenerlo tal como ha sido y como es, por toda la eternidad, gritando insaciablemente da capo! [ique se repita!] no sólo a sí mismo, sino a la obra y al espectáculo entero, y no sólo a un espectáculo, sino, en el fondo, a aquel que tiene necesidad precisamente de ese espectáculo $-\mathrm{y}$ lo hace necesario: porque una y otra vez tiene necesidad de sí mismo -y lo hace necesario - ¿Cómo? ¿Y esto no sería - circulus vitiosus deus [dios es un círculo vicioso]? ${ }^{76}$

Concluyendo, en atención a estas últimas cuestiones suscitadas por la reflexión sobre el eterno retorno es forzoso indagar acerca de si lo uno tiene que ser capaz para vivir según este nuevo principio que nos ofrece Nietzsche en su doctrina. Si retomamos el aforismo 341 de La gaya ciencia ya tenemos lo esencial: «¿cómo necesitarías amarte a ti mismo y a la vida, para no desear nada más que esta última y eterna confirmación y ratificación?». La condición sine qua non para vivir el eterno retorno es tener la fortaleza del amor a sí mismo y a la vida. El amor como afirmación de la vida, amor noble, se opone al odio de los resentidos, los debilitados en su voluntad de afirmarse a sí mismos y a la vida. El amor noble crea incluso cuando tiene que destruir, al paso que el odio resentido todo envenena porque en todo mira la enemistad, en todo mira su incapacidad de

76 MABM, 56. 
ser fuerte para amar de verdad y la verdad del mundo. Se crea el odio un amor que desprecia y desvaloriza, un amor que ya no crea, sino niega. Su amor es el odio a la vida como amor a la negación que afirma el más allá de los trasmundos. El amor transmundano de estos resentidos es el amor culpable y débil de voluntad en el que ya no se está capacitado para vivir el mundo y la vida como afirmación y gozo, en la alegría y gozo y en dolor y privación.

Hay que recordar que el tipo de felicidad propia del amor noble no es un regalo, sino que es la condición de uno mismo. Uno es lo que es y es llamado a ser lo que es: esta es la verdad antropológica del pensamiento del eterno retorno. Entonces, participamos del movimiento de las fuerzas con lo que somos. El hacerse en la vida es el participar en las muchas posibilidades que las diferentes conformaciones y circunstancias nos presentan. Nuestra libertad reside en el crear en este juego de posibilidades según el grado de afirmación que soportamos y deseamos crearnos. El más alto nivel de afirmación es la aceptación del pensamiento del eterno retorno: el querer siempre, incluso lo más duro, pero siempre querer. Pero, no es un querer psicológico, en cuanto volición - lo que ya está refutado, sino el querer que quiere algo, quiere la vida como afirmación y voluntad de poder. En tal afirmación se encuentra la redención de la culpa en cuanto a deuda y pecado. La redención del querer de otro y del querer la nada, sea porque se venera lo más santo, sea por temor.

El eterno retorno rompe con lo que nos mantenía atados a la cadena del ser, liberándonos para el participar participante del juego del devenir. El pensamiento del eterno retorno es liberador de toda concepción moral y metafísica que aprisiona el mundo y la libertad en un más allá de la tierra y del hombre. El hombre y la tierra celebran su reencuentro en esta doctrina y tal es el mensaje que redime el hombre de la culpa. Liberada una deuda para con los ídolos del idealismo, del «mundo verdadero», de la libertad de la voluntad, del ser, de la cosa en sí, o sea, liberada de la deuda con relación al Dios como representación mayor e imagen (ídolo) de esta configuración que la debilidad creó para sí como más allá, el mundo puede seguir siendo tan sólo lo que es, recupera su inocencia, su verdad y el hombre puede seguir devoto tan sólo al amor que se entrega 
a la tierra y a sí mismo. Su existencia pierde la noción de castigo que la antigua creencia le infligía y gana con esta nueva valoración el sentido de vida plena. Es esta liberación la que torna posible la gran responsabilidad que no es otra cosa que el gran amor por la vida liberada de los trasmundos y liberada para la contemplación y creación de la vida, pues se quiere como afirmadora de lo que es. No castigo, sino creación. No el ser estático, sino el movimiento del devenir. No el pecado, sino la locura dionisíaca por la afirmación de la vida.

En esta nueva responsabilidad, noble y aristocrática, en el sentido propio del hombre soberano y verdaderamente libre y afirmador, no hay espacio, por supuesto, para el resentimiento, sino y solamente para la afirmación. El combatir el resentimiento en lo que tiene de más esencial, el odio por la vida, hace del eterno retorno el pensamiento más liberador al que podría haber llegado Nietzsche. Es plenamente consecuente con su pensar genealógico, la conclusión más natural con relación a lo que debe significar el paso atrás liberador en la genealogía de la culpa o su redención. Sin embargo, a lo que nos obliga el pensamiento del eterno retorno es a reconocer que todos estos momentos son absolutamente necesarios y que las fuerzas que en él actúan son las que son y no hay más remedio que seguir luchando y conviviendo con ellas. No se trata de un pensamiento consolador, ni realista, sino un pensamiento liberador y creativo desde el reconocimiento de la verdad sobre lo que es la vida: un juego. Y como nos recuerda Zaratustra: «para el juego del crear se precisa un santo decir-sí: el espíritu quiere ahora su voluntad, el retirado del mundo conquista ahora su mundo» ${ }^{77}$.

¿Estáis ahora preparados? Tenéis que haber vivido y pasado por cada grado de duda y haberos bañado con deleite en corrientes gélidas - de lo contrario no tenéis derecho alguno a este pensamiento; iquiero defenderme de los creyentes fáciles y de los exaltados! ¡Quiero defender mi pensamiento de antemano! Él ha de ser la religión de las almas más libres, joviales y sublimes - ¡una pradera entre hielo dorado y cielo puro! ${ }^{78}$

$77 \mathrm{Z}$, «De las tres transformaciones».

78 1881, 11[339]. 
Las exigencias han sido planteadas, pero podríamos con un aforismo de la época de Zaratustra sintetizar a modo de esquema lo que se hace menester realizar.

Para soportar el pensamiento del retorno:

se requiere libertad con respecto a la moral, nuevos medios contra el hecho del dolor (concebir el dolor como instrumento, como padre del placer - no hay una conciencia sumativa del displacer)

el goce de toda especie de incertidumbre y experimentabilidad como contrapeso de aquel extremo fatalismo

la abolición del concepto de necesidad

la abolición de la «voluntad»

la abolición del «conocimiento en sí»

máxima elevación de la conciencia de la fuerza en el hombre en cuanto aquel que crea al superhombre ${ }^{79}$.

Y en cuanto a los medios para soportarlo, añadimos lo que viene a continuación de este último aforismo. El camino para el eterno retorno es la transvaloración de todos los valores. Este cambio quiere decir: «el placer ya no en la certeza, sino en la incertidumbre; ya no "causa y efecto", sino lo constantemente creativo; ya no la voluntad de conservación, sino de poder, etc.; ya no el humilde giro "todo es meramente subjetivo”, sino “¡también es nuestra obra!" ¡Estemos orgullosos de ello! $»^{80}$.

$791884,26[283]$.

80 1884, 26[284]. Hemos modificado la forma original en que el aforismo fue elaborado por Nietzsche incluyendo una nueva puntuación con el objetivo de adaptar el texto a nuestra redacción sin cambiarle el sentido original. 
BiBLIOGRAFÍA

\section{Obras de Friedrich Nietzsche}

\section{Edición crítica}

Sämtliche Werke. Kristische Studienausgabe in 15 Bänden. Hrg. von Giorgio Colli und Mazzino Montinari. Munchen, Berlin, New York, Deutscher Taschenbuch Verlag und Walter de Gruyter, 1980.

\section{Traducciones utilizadas}

a) Las de A. Sánchez Pascual publicadas por Alianza Editorial Consideraciones Intempestivas, 1. David Strauss, el confesor y el escritor, Madrid: Alianza Editorial 2000.

El nacimiento de la tragedia, Madrid: Alianza Editorial 2001. Así habló Zaratustra, Madrid: Alianza Editorial 2001.

Más allá del bien y del mal, Madrid: Alianza Editorial 2001. La genealogía de la moral, Madrid: Alianza Editorial 1995. Crepúsculo de los ídolos, Madrid: Alianza Editorial 2001. El Anticristo, Madrid: Alianza Editorial 2001. Ecce Homo, Madrid: Alianza Editorial 2001.

b) Otras ediciones

Consideraciones Intempestivas, II. Sobre la utilidad y el perjuicio de la historia para la vida, trad. Germán Cano, Madrid: Editorial Biblioteca Nueva 1999.

Consideraciones Intempestivas, III. Schopenhauer como educador, trad. Jacobo Muñoz, Madrid: Editorial Biblioteca Nueva 2001.

El culto griego a los dioses (Con el apéndice: Cómo se llega a ser filólogo), trad. Diego Sánchez Meca, Madrid: Alderabán 1999.

Consideraciones Intempestivas, IV. Richard Wagner en Bayreuth en Escritos sobre Wagner, trad. Joan B. Llinares Chover, Madrid: Editorial Biblioteca Nueva 2003.

Humano demasiado humano. Un libro para espíritus libres. I y II, trad. Alfredo Brotons Muñoz, Madrid: Akal 1996. 
La Gaya Ciencia, trad. Charo Grago y Ger Groot, Madrid: Akal 2001.

Aurora, trad. Germán Cano, Madrid: Biblioteca Nueva 2000.

El caso Wagner. Un problema para músicos, en: Escritos sobre Wagner, trad. Joan B. Llinares Chover, Madrid: Editorial Biblioteca Nueva 2003.

Nietzsche contra Wagner. Documentos de un psicólogo, en: Escritos sobre Wagner, trad. Joan B. Llinares Chover, Madrid: Editorial Biblioteca Nueva 2003.

c) Escritos y fragmentos póstumos

Sobre verdad y mentira en sentido extramoral, trad. Luis Ml. Valdés y Teresa Orduña, Madrid: Tecnos 1994.

Sobre el porvenir de nuestras instituciones educativas, trad. Carlos Manzano, Barcelona: Tusquets 2000.

Cinco prólogos para cinco libros no escritos, trad. Alejandro del Río Herrmann, Madrid: Arena Libros 1999.

Fragmentos Póstumos: 1876 hasta invierno de 1877-1878, en: Humano demasiado humano. Un libro para espíritus libres. I y II, trad. Alfredo Brotons Muñoz, Madrid: Akal 1996.

Fragmentos póstumos: primavera de 1878 hasta noviembre de 1879, en: Humano demasiado humano. Un libro para espíritus libres. I y II, trad. Alfredo Brotons Muñoz, Madrid: Akal 1996.

Antología, trad. Joan B. Llinares Chover y Germán A. Meléndez Acuña, Barcelona: Ediciones Península 2003.

Sabiduría para pasado mañana. Selección de Fragmentos póstumos (1869-1889), trad. Diego Sánchez Meca, Madrid: Tecnos 2001. [Hemos consultado la traducción de los fragmentos posteriores a 1879].

II. Otras fuentes

PLATÓN, La República, trad. José Manuel Pablón y Manuel Fernández-Galliano, Madrid: Alianza 1990.

I. KANT, Fundamentación de la metafísica de las costumbres, trad. Manuel García Morente, Madrid: Encuentro 2003. 
I. KANT, Crítica de la razón pura, trad,. Pedro Ribas, Madrid: Alfaguara, 2003.

I. KANT, Crítica de la razón práctica, trad. E. Miñana y Villagrasa y Manuel García Morente, Salamanca: Sígueme 1997.

A. SCHOPENHAUER, El mundo como voluntad y representación, trad. Roberto R. Aramayo, Barcelona: FCE 2003.

A. SCHOPENHAUER, Los dos fundamentos de la ética, trad. Pilar López de Santa María, Madrid: Siglo XXI Editores 2002.

M. HEIDEGGER, Nietzsche, Pfullingen 1961. Edición castellana: Nietzsche, trad. Juan Luis Vermal, Barcelona: Ediciones Destino 2001.

M. HEIDEGGER, Ser y tiempo, trad. Jorge Eduardo Rivera Cruchaga, Santiago de Chile: Editorial Universitaria 1997.

M. HEIDEGGER, «La frase de Nietzsche "Dios ha muerto"», en: Caminos de bosque, trad. H. Cortés y A. Leyte, Madrid: Alianza 1995.

M. HEIDEGGER, ¿Qué significa pensar?, trad. H. Kahnemann, Buenos Aires: Nova 1978.

M. HEIDEGGER, «¿Quién es el Zaratustra de Nietzsche?», en: Conferencias y artículos, trad. Eustaquio Barjau, Barcelona: Ediciones del Serbal 1994.

M. HEIDEGGER, «La época de la imagen del mundo», en: Caminos de bosque, trad. H. Cortés y A. Leyte, Madrid: Alianza 1995.

III. Sobre Nietzsche

R. ÁVILA CRESPO, Nietzsche y la redención del azar, Granada: Universidad 1986.

R. ÁVILA CRESPO, Identidad y tragedia. Nietzsche y la fragmentación del sujeto, Barcelona: Crítica 1999.

M. BARRIOS CASARES, La voluntad de poder como amor, Barcelona: Ediciones del Serbal 1990.

M. BARRIOS CASARES, Voluntad de lo trágico, Sevilla: Er 1993.

E. BISER, Nietzsche y la destrucción de la conciencia cristiana, Salamanca: Sígueme 1974.

J. L. BORGES, Historia de la eternidad, Madrid: Alianza 1978. 
M. CACCIARI, Desde Nietzsche. Tiempo, arte, política, Buenos Aires: Editorial Biblos 1994.

G. CANO, Como un ángel frío. Nietzsche y el cuidado de la libertad, Valencia: Pre-Textos 2000.

G. CANO, Nietzsche y la crítica de la Modernidad, Madrid: Biblioteca Nueva 2000.

G. COLLI, Introducción a Nietzsche, trad. Isidro Herrera Baquero y Alejandro del Río, Valencia: Pre-Textos 2000.

G. COLLI, Después de Nietzsche, trad. C. Artal, Barcelona: Anagrama 1988.

J. CONILL, El poder de la mentira. Nietzsche y la política de la transvaloración, Madrid: Tecnos 1997.

M. B. CRAGNOLINI y G KAMINSKY (eds.), Nietzsche actual e inactual, Buenos Aires: Universidad de Buenos Aires 1996.

G. DELEUZE, Nietzsche et la philosophie, Paris: Quadrige PUF 2003. Edición castellana: Nietzsche y la filosofía, Barcelona: Anagrama 1971.

G. DELEUZE, Nietzsche, trad. Isidro Herrera Baquero y Alejandro del Río Herrmann, Madrid: Arena Libros 2000.

D. FRANCK, Nietzsche et l'ombre de Dieu, París: PUF 1998.

J. GRANIER, Le problème de la vérité dans la philosophie de Nietzsche, Paris: PUF 1966.

J. GRANIER, Nietzsche, Paris: PUF 1982.

P. HÉBER SUFFRIN, Le Zarathoustra de Nietzsche, Paris: PUF 1988.

P. KLOSSOWSKI, Nietzsche et le cercle vicieux, Paris: PUF 1969. Edición castellana: Nietzsche y el círculo vicioso, Barcelona: Seix Barral 1972.

J. B. LLINARES, Nietzsche, 100 años después, Valencia: Pre-textos 2002.

K. LÖWITH, Von Hegel zu Nietzsche. Der Revolutionäre Bruch im Denken des XIX. Jahrhunderts, Zurich: Verlag 1941. Edición castellana: De Hegel a Nietzsche. La quiebra revolucionaria del pensamiento del siglo XIX, Buenos Aires: Sudamericana 1968.

J. M. NAVARRO CORDÓN, «Kant. Sendas de la libertad», en: Javier ECHEVERRÍA (ed.), Enciclopedia Iberoamericana de Filosofía («Del Renacimiento a la Ilustración II»), Madrid: Trotta-CSIC 2000. 
J. M. NAVARRO CORDÓN, «Nietzsche: de la libertad del mundo», en: José Luis VILLACAÑAS BERLAGA (ed.), Enciclopedia Iberoamericana de Filosofía («La filosofía del siglo XIX»), Madrid: TrottaCSIC 2001.

J. QUESADA, Un pensamiento intempestivo. Ontología, estética y politica en F. Nietzsche, Barcelona: Anthropos 1988.

O. REBOUL, Nietzsche, critique de Kant, Paris: PUF 1974. Edición castellana: Nietzsche, crítico de Kant, Barcelona: Anthropos-Universidad Autónoma Metropolitana 1993.

D. SÁNCHEZ MECA, En torno al superhombre. Nietzsche y la crisis de la modernidad, Barcelona: Anthropos-Universidad de Murcia 1989.

D. SÁNCHEZ MECA, «Perspectivas actuales de interpretación del Übermensch nietzscheano», Revista de filosofía 14 (1992/I).

O. SCHUTE, Más allá del nihilismo. Nietzsche sin máscaras, trad. Eloy Rodríguez Navarro, Madrid: Ediciones Laberinto 2000.

P. VALADIER, Nietzsche et la critique du christianisme. Edición castellana: Nietzsche y la crítica del cristianismo, trad. Eloy Rodríguez Navarro, Madrid: Ediciones Cristiandad 1982.

P. VALADIER, La Iglesia en proceso. Catolicismo y sociedad moderna, Santander: Sal Terrae 1990.

G. VATTIMO, Introducción a Nietzsche, trad. J. Binaghi, Barcelona: Península 1987. Edición portuguesa: Introdução a Nietzsche, Lisboa: Editorial Presença 1990.

G. VATTIMO, Las aventuras de la diferencia. Pensar después de Nietzsche y Heidegger, Barcelona: Península 2002.

G. VATTIMO, El sujeto y la máscara. Nietzsche y el problema de la liberación, Barcelona: Península 1998.

G. VATTIMO, Más allá del sujeto. Nietzsche, Heidegger y la hermenéutica, Barcelona: Paidós 1989.

G. VATTIMO, Ética de la interpretación, Buenos Aires: Paidós 1992.

J. L. VERMAL, La crítica de la metafísica en Nietzsche, Barcelona: Anthropos 1987.

V. VITIELLO, Utopia del nichilismo. Tra Nietzsche e Heidegger, Nápoles 1983. 


\section{RESUMEN}

Este ensayo tiene como finalidad una aproximación al pensamiento del eterno retorno de lo mismo de Nietzsche, no considerándolo como un postulado científico, sino como un modo de pensar el mundo y de estar en él. El pensamiento del eterno retorno se presenta como una redención de la culpa, de lo pasado, y como una afirmación del mundo y de sí mismo, contrario por ende a todo pensamiento que desprecie la vida. Este pensamiento es la medida según la cual se establece el valor de la vida misma, según el grado de fortaleza de cada hombre.

Palabras clave: pensamiento del eterno retorno de lo mismo; culpa; redención; soledad; fuerza.

\section{ABSTRACT}

This essay aims an approximation to the thought of eternal return of the same in Nietzsche, not treating it as a scientific postulate, but as a way of think about the world and to be in it. The thought of eternal return is presented as a redemption from the guilt and the past, and as an affirmation of the world and of itself, therefore contrary to any thought that despise life. This thought is the measure that establishes the value of life itself, depending on the degree of strength of each man.

Keywords: thought of the eternal return of the same; guilt; redemption; loneliness; strength. 